\title{
Design and validation of integrated clamping interfaces for post-processing and robotic handling in additive manufacturing
}

\author{
Julian Ferchow $^{1} \cdot$ Dominik Kälin $^{2} \cdot$ Gokula Englberger $^{2} \cdot$ Marcel Schlüssel $^{3} \cdot$ Christoph Klahn $^{1} \cdot$ Mirko Meboldt $^{2}$
}

Received: 3 May 2021 / Accepted: 13 September 2021

(c) The Author(s) 2022, corrected publication 2022

\begin{abstract}
Additive manufacturing (AM), particularly laser-based powder bed fusion of metals (LPBF), enables the fabrication of complex and customized metallic parts. However, $20-40 \%$ of the total manufacturing costs are usually attributed to postprocessing steps. To reduce the costs of extensive post-processing, the process chain for AM parts has to be automated. Accordingly, robotic gripping and handling processes, as well as an efficient clamping for subtractive machining of AM parts, are key challenges. This study introduces and validates integrated bolts acting as a handling and clamping interface of AM parts. The bolts are integrated into the part design and manufactured in the same LPBF process. The bolts can be easily removed after the machining process using a wrench. This feasibility study investigates different bolt elements. The experiments and simulations conducted in the study show that a force of $250 \mathrm{~N}$ resulted in a maximum displacement of $12.5 \mu \mathrm{m}$. The milling results of the LPBF parts reveal a maximum roughness value, $\mathrm{Ra}$, of $1.42 \mu \mathrm{m}$, which is comparable to that of a standard clamping system. After the bolt removal, a maximum residual height of $0.067 \mathrm{~mm}$ remains. Two case studies are conducted to analyze the form deviation, the effect of bolts on build time, and material volume and to demonstrate the application of the bolts. Thus, the major contribution of this study is the design and the validation of standardized interfaces for robotic handling and clamping of complex AM parts. The novelties are a simple and clean interface removal, less material consumption, less support structure required, and finally an achievement of a five-side tool accessibility by combining the interfaces with a three-jaw chuck.
\end{abstract}

Keywords Additive manufacturing $\cdot$ Post-processing $\cdot$ Clamping $\cdot$ Robotic handling $\cdot$ Laser-based powder bed fusion

\section{Introduction}

Additive manufacturing (AM), particularly laser-based powder bed fusion of metals (LPBF), has wide industrial applications. Advantages of AM are the production of customized and highly complex designs at reasonable cost [1].

However, the LPBF technology incurs certain limitations. Deradjat and Minshall [2] identified the extensive postprocessing efforts as the major challenges. A typical postprocessing of LPBF parts involves the following four steps:

Julian Ferchow

ferchow@inspire.ethz.ch

1 Inspire AG, Ipdlz, Leonhardstrasse 21, 8092 Zurich, Switzerland

2 ETH Zürich, pdlz, Leonhardstrasse 21, Zurich 8092, Switzerland

3 Gressel AG, Schützenstrasse 25, 8355 Aadorf, Switzerland removal of powder from the cavities and support structures, heat treatment for stress relaxation, separation of parts from the base plate, and the manual and cost-intensive removal of the support structure. Moreover, the near-net-shape (NNS) and functional surfaces are still rough and imprecise and thus require finishing. All these aspects lead to challenging machining efforts to ensure acceptable part quality for series production in end-user applications.

To reduce machining efforts, Flynn et al. [3] proposed a promising approach that sequentially combines the AM process and subtractive manufacturing process.Using this method, Manogharan et al. [4] showed that the LPBF machine utilization can be kept constant, and Le et al. [5] indicated that the tool access can be improved.

Despite the recent developments made in combining $\mathrm{AM}$ and sequentially subtractive manufacturing, the cost of post-process steps is still $20-40 \%$ of manufacturing costs [2][2][2][2]. Therefore, AM is mostly used for low batch sizes. Figure 1 shows the extensive manual process steps 
Fig. 1 Conventional LPBF postprocessing chain highlighting the problematic removal of support structures and the required part clamping for machining

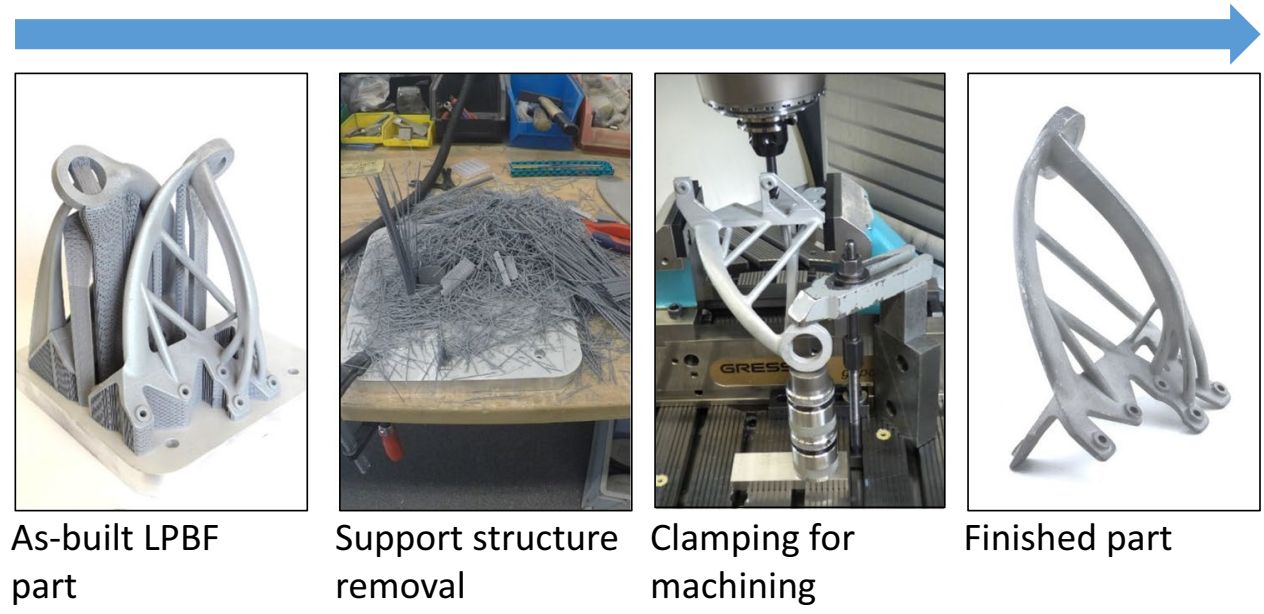

conducted for an LPBF part (which in this case is a lightweight bracket designed by Klahn et al. [9]), including the manual support structure removal and extensive manual clamping.

Generally, post-processing requires manual steps because complex, individualized AM parts are difficult to grip, handle, and clamp in automated processes. Gripping and handling induce low forces and are required to transport the LPBF part between the process steps [10]. However, clamping induces a high force to hold the part for stable machining. Kushnarenko [11] described clamping for surface machining as a bottleneck in mass customization within the AM process chains because of the complexity of AM designs. Often, complex AM parts require individual fixtures for clamping, which add high costs and hinder customization.

The requirement of machining NNS manufactured parts, such as AM parts, is already known from other NNS processes, such as casting and forging. The examples for this are presented in the casting handbook presented by Blair and Stevens [12]. Previously, studies have adopted clamping solutions from the casting domain into the AM domain. For instance, Boonsuk and Frank [13] presented a methodology for developing sacrificial interfaces for clamping. The general concept of integrating sacrificial holding interfaces into fixtures is similar to that of the approach already used for casted or forged parts [14].

However, the interfaces for AM parts, proposed by Boonsuk and Frank [13], require considerably more additional materials, building time, and support structures. Moreover, they require extensive manual steps to remove the interfaces after the machining process.Additionally, it is tedious to place the interfaces during the design process on the AM part. Furthermore, such interfaces significantly restrict the accessibility of tools. [10-13, 15, 16]

Therefore, parallel surfaces are commonly used as clamping interfaces on AM parts, e.g., those described by Leutenecker-Twelsiek [17]. Figure 2 visualizes the current state-of-the-art technique for clamping parts between two parallel jaws during machining. The key issues of such clamping systems include reduced tool accessibility, requirement for additional materials for the two parallel surfaces, and increased stiffness of LPBF parts to transfer the clamping and milling forces. A case study conducted by Schmelzle et al. [18] emphasized the consideration of the two parallel surfaces at an early stage of the design process. This restricts the design freedom of the LPBF parts. Complex AM parts often require extensive fixtures, in addition to simple parallel surfaces, for stable post-machining.

In addition to using parallel jaws as clamping systems, other types of clamping systems are commercially available for AM parts and have been described in the literature. Bi and Zhang [19] provided an overview of flexible clamping systems. For example, form-closure clamping systems are commercially available at Lang Technik [20]. Tohidi and AlGeddawy [21] described modular and flexible fixtures. Bakker et al. [22] analyzed multi-finger modules and a reconfigurable system. Adhesives and resins are other alternatives for gripping and holding a workpiece during machining [21, 23].

Despite the above described developments made in AM-integrated interfaces and clamping systems, only a few products are currently used for AM. This is because most of them have disadvantages such as the extensive manual effort required in installing them or the high clamping forces that can damage fragile AM structures.

AM enables the production of complex designs and customized parts, which often require to be post-processed. However, the existing fixtures do not meet all requirements of AM post-processing, and thus an improved clamping concept is required to post-process the complex design and customized parts at low costs within a short lead time, particularly after the removal of the built plate. 
Fig. 2 Use of parallel surfaces to clamp complex AM parts between jaws

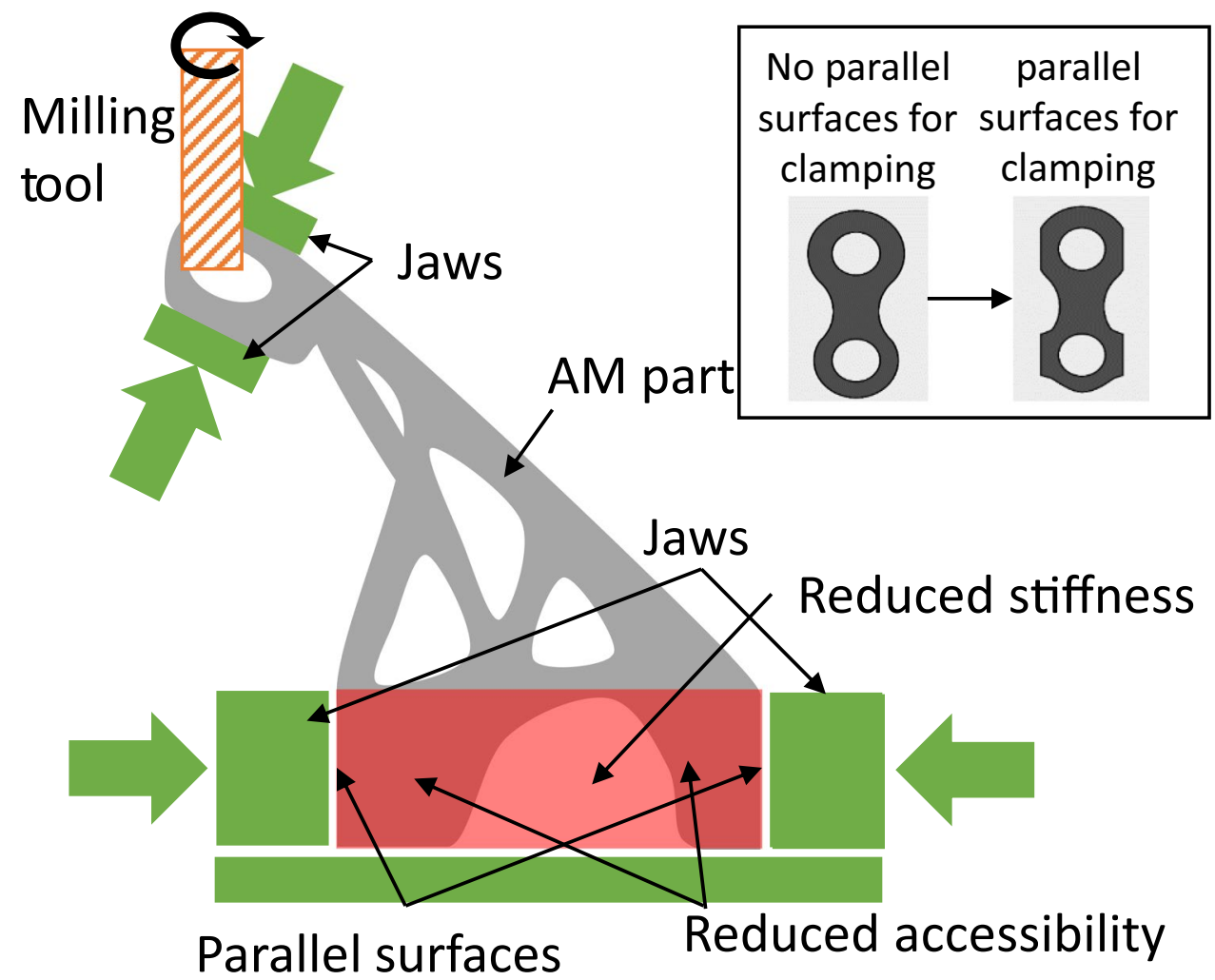

Compared to the studies conducted in the fields of casting [25], subtractive manufacturing [26], and AM [11, 13], this study contributes the following novelties:

- Applicable interface design for a large range of complex AM geometries

- Simple and clean interface removal because of predefined notches

- Requirement of less material consumption and support structure

- Achievement of five-side tool accessibility because of the combination of the interfaces with the three-jaw chucks provided by Relea et al. [27] and Schlüssel et al. [28]

The machine interface of the integrated bolts used in this study is the three-jaw chuck invented by Schlüssel et al. [28]. It is commercially available since 2019. A fixture welds three bolts on the AM part, which provide an interface to the three-jaw chuck and to the handling systems. Relea et al. [27] investigated the feasibility of a three-jaw chuck clamping system for conventionally manufactured parts with welded bolts. They evaluated it as a promising and stable clamping concept, which increases the tool accessibility. Figure 3 shows the concept of integrated bolts.

This study aims to (i) introduce the concept of AMintegrated bolts, (ii) validate the concept by investigating the compliance, the milling roughness and shear-off performance, and (iii) demonstrate the practical applicability of the bolts through two case studies. These case studies investigate the additional build time and material
Fig. 3 a Test samples in the AM-build direction and $\mathbf{b}$ threejaw chuck

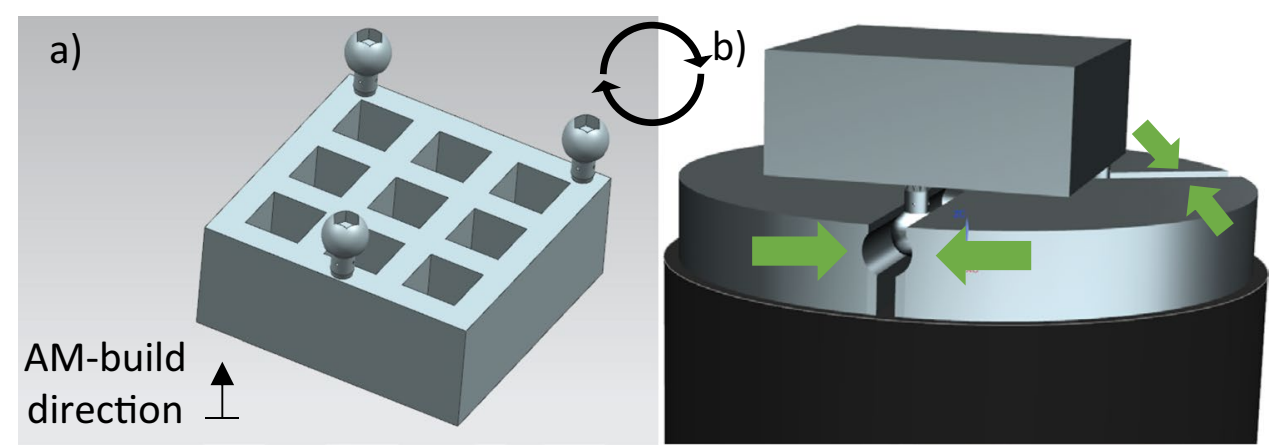


consumption incurred. Hence, this study makes the following contributions to the literature.

- Compliance experiment and simulation of interfaces

- Analysis of milling behavior

- Investigation of removal of torque and remaining material

- Demonstration of practical applicability through case studies

- Analysis of part deformation

- Evaluation of additional LPBF building time required for bolts

This study is structured as follows. Section 2 introduces the concept and design of the integrated bolts. Section 3 describes the materials and methods used to generate the results. Section 4 shows the results of the compliance experiment, compliance simulation, and the milling and shear-off experiments. Section 5 presents two case studies, which demonstrate the application of the bolts, effect of bolts on build time and material volume, and the part deformation.
Section 6 discusses the results. Finally, Sect. 7 concludes the study.

\section{Design of AM-integrated bolts}

The bolts are integrated into the 3D model of the AM part during the design and build job preparation. A schematic of the post-processing is depicted in Fig. 4. Here, the bolts are placed on the opposite sides of the supports, thus allowing suitable accessibility for removing the support structure. To ensure proper robotic handling and a stable machining process without chatter marks, a rigid connection is required between the functional ball interface and AM part. The machining process introduces tensile and compressive stresses, as well as a bending stress, on the bolts. Hollow shafts are used for a straight force transmission from the machined to the clamping system without stress accumulation.
Fig. 4 Automated process chain, including gripping, clamping, and handling, as well as milling and bolt removal

\section{a) Gripping}

(1)

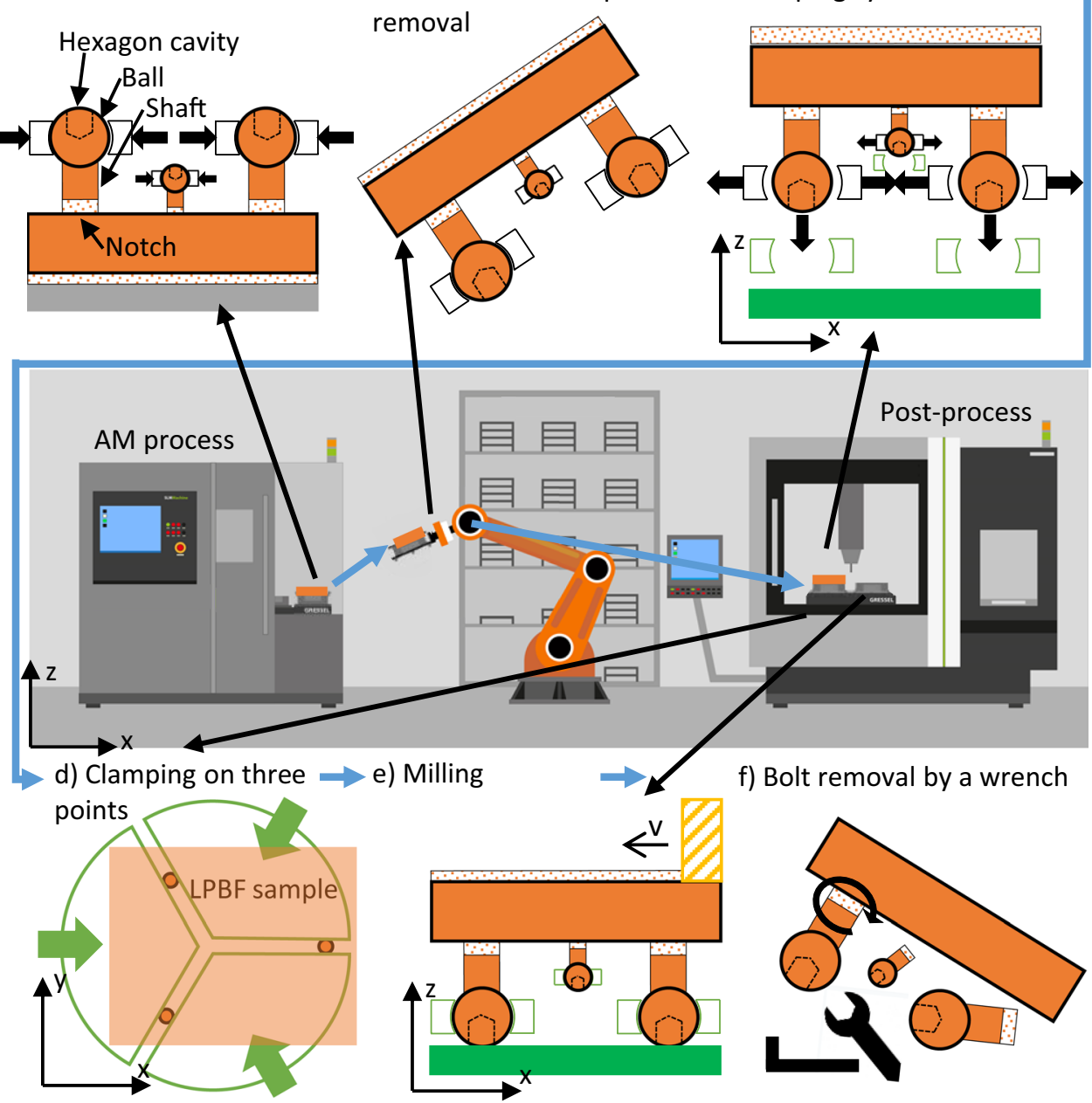


After the machining process, the bolts can be sheared off using a hexagonal wrench. The predefined notches are implemented in the design to transmit the internal introduced tensile, compressive, and bending loads during machining. For easy removal, they are designed as pre-defined breaking points under torsional load. The torsional stress is accumulated at the notches right at their connection with the AM part to break with the minimum residual material. To introduce torsional load, a hexagonal cavity in the functional ball is designed for obtaining an Allen key. In the experiments, the Allen key allows more control over the load introduction without additional bending of the shaft. Another possible interface is the presence of parallel surfaces on the shaft for an open-ended wrench.

A functional ball serves as an imprinted interface, enables self-centering, and is independent of the clamping orientations. Furthermore, the clamping force can be applied in various radial orientations on the spherical geometry of the ball; hence, it compensates for smaller deviations in the manufacturing process.

Figure 5 shows the freedom of positioning the AM part. The clamping system holds the three bolts, which is the minimum number of bolts required to meet the positive location criterion. The three jaws clamp the three bolts without any deformation for all six degrees of freedom. Because of the self-centering of the AM part, its position is explicitly defined, and it can be transferred from the 3D model to the post-process such as a milling machine. However, the thermally induced deformation of the LPBF process should be considered for the position accuracy. Therefore, the arrangement of the clamping system enables a large design freedom when placing the bolts in the AM part [27]. Several factors have to be considered to select suitable attachment points of the bolts. Important criteria for the attachment points are the function of the AM part surface, the tool accessibility, the manufacturability of the bolts, the distance between the bolts, and the stability of the AM part.

\section{Material and methods}

The feasibility study investigated the performance of bolts on test samples. The practical performance of the bolt is investigated using two industrial case studies. A vertical shaft orientation was applied on an inspection robot, shown in Sect. 5.1. An inclined shaft orientation was applied on an aircraft bracket, shown in Sect. 5.2. A Concept Laser Mlab Cusing R manufactured all parts of the study from commercially available stainless-steel $316 \mathrm{~L}$ powder. The fiber laser of the Mlab has a wavelength of $1070 \mathrm{~nm}$ and a laser focal diameter of $50 \mu \mathrm{m}$. The LPBF process operates at a layer thickness of $30 \mu \mathrm{m}$, laser power of $90 \mathrm{~W}$, scan speed of $600 \mathrm{~mm} / \mathrm{s}$, and hatch distance of $84 \mu \mathrm{m}$. The samples used in the case studies were tested under the as-build condition without additional heat treatment. The samples, shown in Fig. 3, had dimensions of $50 \times 50 \mathrm{~mm}$ and a height of $20 \mathrm{~mm}$. The experimental approach is plotted in Fig. 6.

The LPBF samples were manufactured with various bolt configurations, as shown in Fig. 7 (left). Figure 7 (right) shows the bolt designs and their dimensions. The two-level factors considered for designing the experiments were notch-type shaft orientation and jaw shape.

For the predefined notch, a continuous and stepwise design was selected. The continuous notch showed a larger connection area between the shaft and LPBF part. However, the stepwise notch showed a much smaller connection area and additional geometrical notches.

The shaft is a hollow tube vertically oriented at $90^{\circ}$ or inclined at $45^{\circ}$ to the build platform. The inclined monolithic bolt requires support structures for overhanging the functional ball. This is accepted for the context of this study for a better comparison between the two orientations. The case study shown in Sect. 5.2 shows a supportfree solution for inclined bolts.
Fig. 5 Freedom of placing the bolts on the three-jaw clamping system: a bolt position of the test sample; b further examples of bolt positions

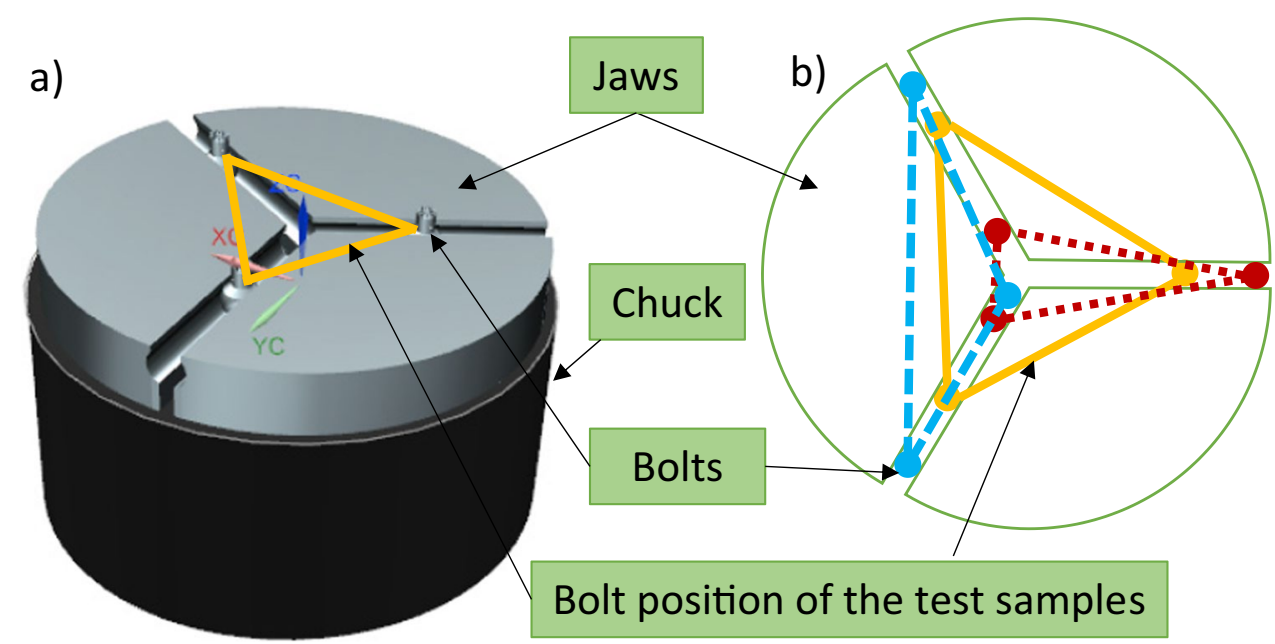




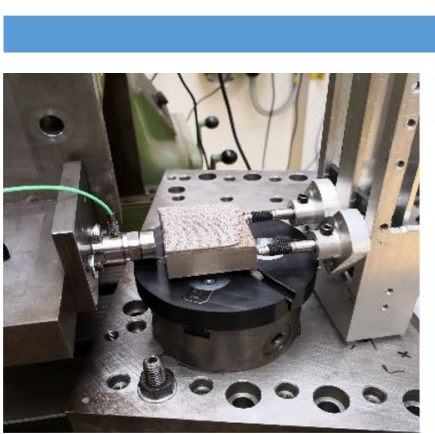

Compliance experiment (Section 4.1)

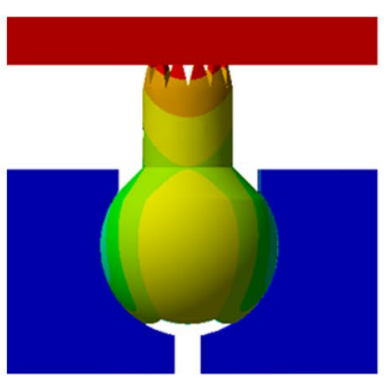

Compliance simulation (Section 4.2)

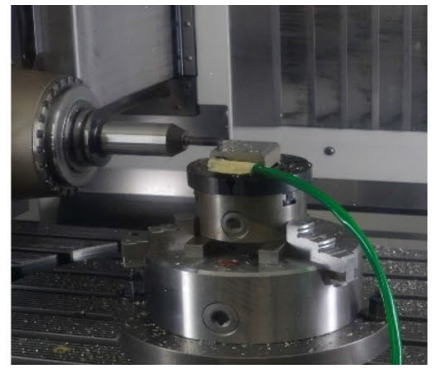

Milling (Section 4.3)

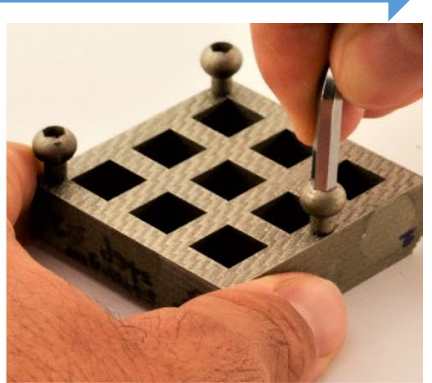

Shear-off

(Section 4.4)

Fig. 6 Experimental approach

Type 1

\begin{tabular}{|c|c|c|}
\hline $\begin{array}{l}\text { Notch } \\
\text { LPBF part - } \\
\text { bolt } \\
\text { connection }\end{array}$ & Continuous & Stepwise \\
\hline $\begin{array}{c}\text { Shaft } \\
\text { Notch - } \\
\text { functional ball } \\
\text { connection }\end{array}$ & Vertical & Inclined \\
\hline $\begin{array}{l}\frac{\text { Interface }}{\text { Bolt - }} \\
\text { Clamping } \\
\text { system }\end{array}$ & Round & Polygon \\
\hline
\end{tabular}

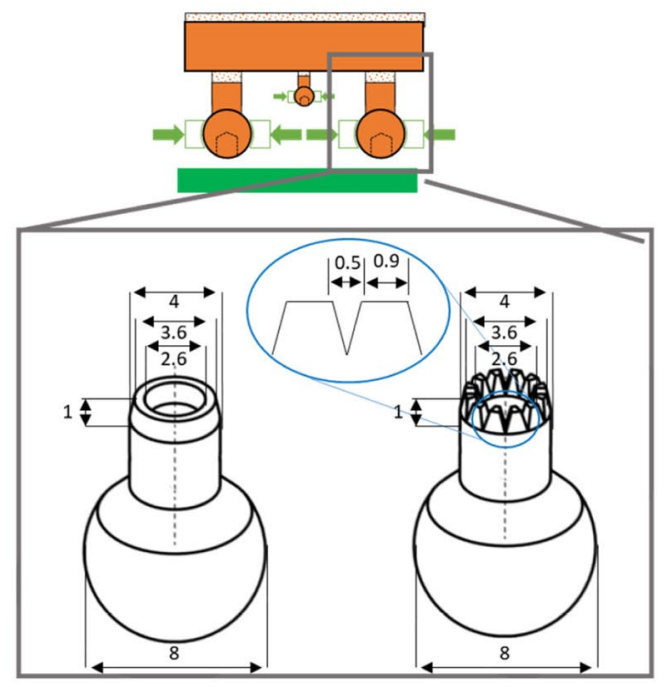

Fig. 7 (Left) Various main elements of the bolt. (Right) Dimensions of the bolts

The jaw interface shows two variations: a round jaw and a polygon jaw. The design of the functional ball remains constant. The round jaw contacts a larger area between the functional ball and chuck. However, the polygon jaw contacts a smaller area between the jaws and functional balls, causing larger deformations in the balls.

Furthermore, a two-level full-factorial design of experiment (DoE) was conducted, where the predefined notch, shaft, and two jaw types were used as the input parameters. Eight test samples were required for the complete DoE, and each manufactured sample was used for the entire randomized experimental procedure during clamping. One replicate was conducted for each experimental condition.
Figure 8 shows the symbols and summarizes the sample numbers.

Figure 9 shows the test bench of the compliance experiment with the clamped sample, force sensor, and two displacement sensors. The rigid machine table of an Oerlikon milling machine was used as the test bench. Force was applied by moving the machine slide in the $\mathrm{x}$ direction. A piezo force sensor (9323A from Kistler) measured the force applied on the sample with a tolerance of $\pm 0.5 \mathrm{~N}$. The block and chuck were very stiff compared to the bolts. Therefore, the measured displacement was attributed to the bolt deformation. A three-jaw chuck obtained from Gressel AG clamped the bolts of all LPBF samples with a force 
1

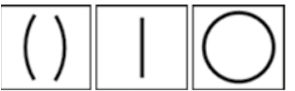

5

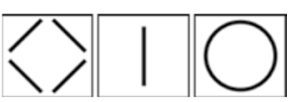

2

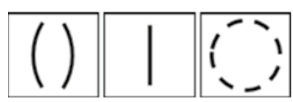

6

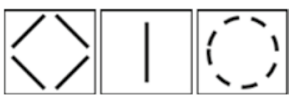

3

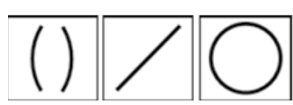

7

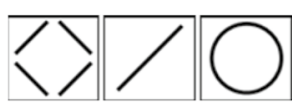

4

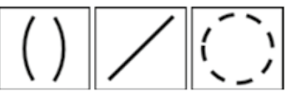

8

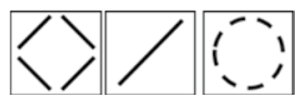

Fig. 8 Summary of the test sample numbers and symbols

of $2.5 \mathrm{kN}$ on each functional ball. A Heidenhain ST 1200 displacement sensor was placed on the opposite side of the load introduction and measured the sample's displacement within a tolerance of $\pm 1 \mu \mathrm{m}$.

NNS production is the primary advantage of AM. Post-processing of AM parts requires little-to-no rough machining, which induces high forces on the machined parts. Therefore, precision finishing is sufficient and most commonly used for AM applications and is known to introduce an $\sim 250 \mathrm{~N}$ force for 3161 . Fortunato et al. [29] determined a maximum milling force of $210 \mathrm{~N}$ and Ozcelik et al. [30] a maximum milling force of $230 \mathrm{~N}$. The compliance experiments investigated two load cases. In the symmetric load case, a maximum force of $1500 \mathrm{~N}$ was applied toward the chuck center. As for the asymmetric load case, it represents the worst load case scenario with an eccentric load introduction of $1000 \mathrm{~N}$. Here, the primary load was introduced on a single bolt. Higher loads would risk large plastic deformations, which would make it impossible to machine samples after compliance test.

A finite-element analysis (FEA) simulation of the compliance complemented the experimental results analyzed the influence of friction and simulated the shear of torque. Ansys R19.2 was used to simulate the static deformation and determine the compliance. The stainless-steel 3161 material was applied in the model. A mesh refinement was performed to determine a suitable mesh size. The mesh size in the rigid areas was set as $2 \mathrm{~mm}$. For the critical area of the ball/jaw connection, a mesh size of $0.3 \mathrm{~mm}$ was used for the balls. For the stepwise intersection of the body/notch, a mesh size of $0.05 \mathrm{~mm}$ was used for the notches. For the continuous intersection of the body/notch, a mesh size of 0.1 was used. For the stick-slip boundary condition between the jaws and balls, a friction coefficient of $\mu=0.8$ was determined in preliminary experiments and applied in this study Fig. 10.

Fig. 9 Compliance experiment

Load introduction measurement

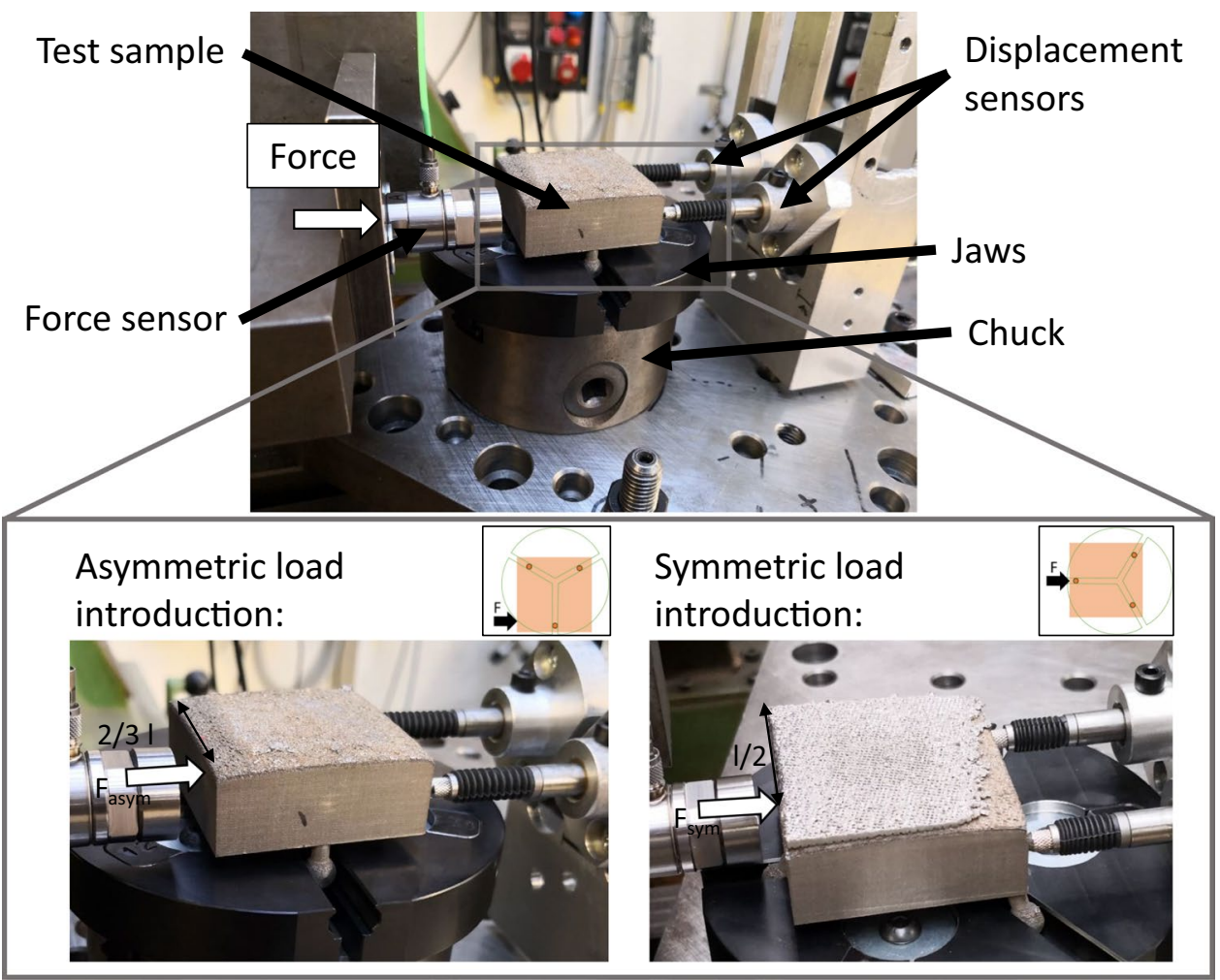




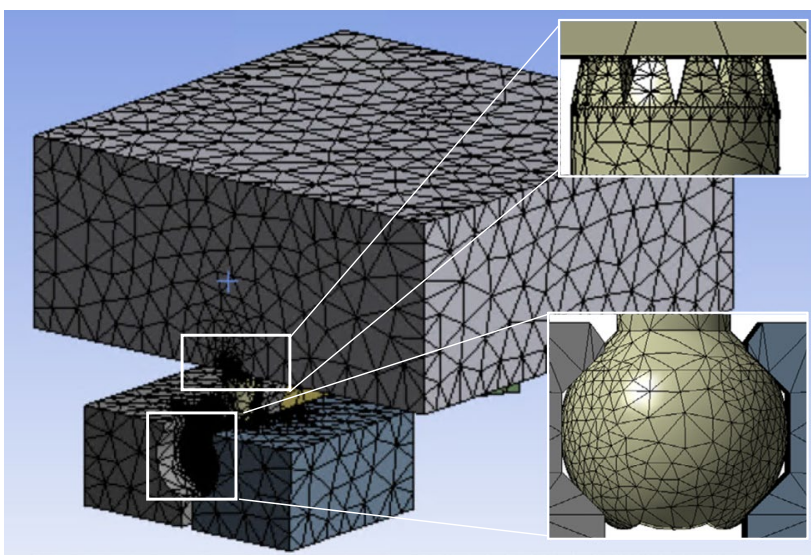

Fig. 10 Mesh used for FEA of rigid AM part, the stepwise shaft, and polygon jaws

A frequency response measurement was performed to evaluate the dynamic behavior of the case studies. The AM parts in the case studies were excited using an impact hammer (Type 9722A500 from Kistler), and a piezoelectric charge accelerometer (Type 4393 from Brüel \& Kjær) was used to measure the response. The masses of the equipment are indicated as follows: sensor $(2.4 \mathrm{~g})$, robotic housing (88 g), and aerospace bracket (65 g). According to Özşahin et al. [31], a lower sensor mass than the part mass has a minor influence on the frequency response measurement of the investigated sample. The sensor signals were analyzed by a LDS Focus II system that allows a sampling rate of $f_{\text {sample }}=12 \mathrm{kHz} / \mathrm{channel}$. Finally, the signal was integrated twice to acquire the frequency response function.

All milling experiments were conducted using a fiveaxis CNC milling machine (DMU 60 monoBlock from DECKEL MAHO) using the CAD/CAM-software Mastercam 2020. All experiments used a cylindrical shank cutter (Fraisa P45355) with a diameter of $10 \mathrm{~mm}$ and four cutting edges for both face and side milling. The cooling lubricant (B-Cool 755 from Blaser SwisslubeAG) is used. The cutting depth was varied between 1 and $3 \mathrm{~mm}$, and the roughness was measured using a confocal laser scanning microscope (Keyence VK-X200K). Figure 11 shows the experimental milling setup, and Table 1 lists the process parameters used in the experiments.

The GOM ATOS Core 200 3D scanner measured the deformation of parts in the case study. The 3D
Fig. 11 Experimental milling setup

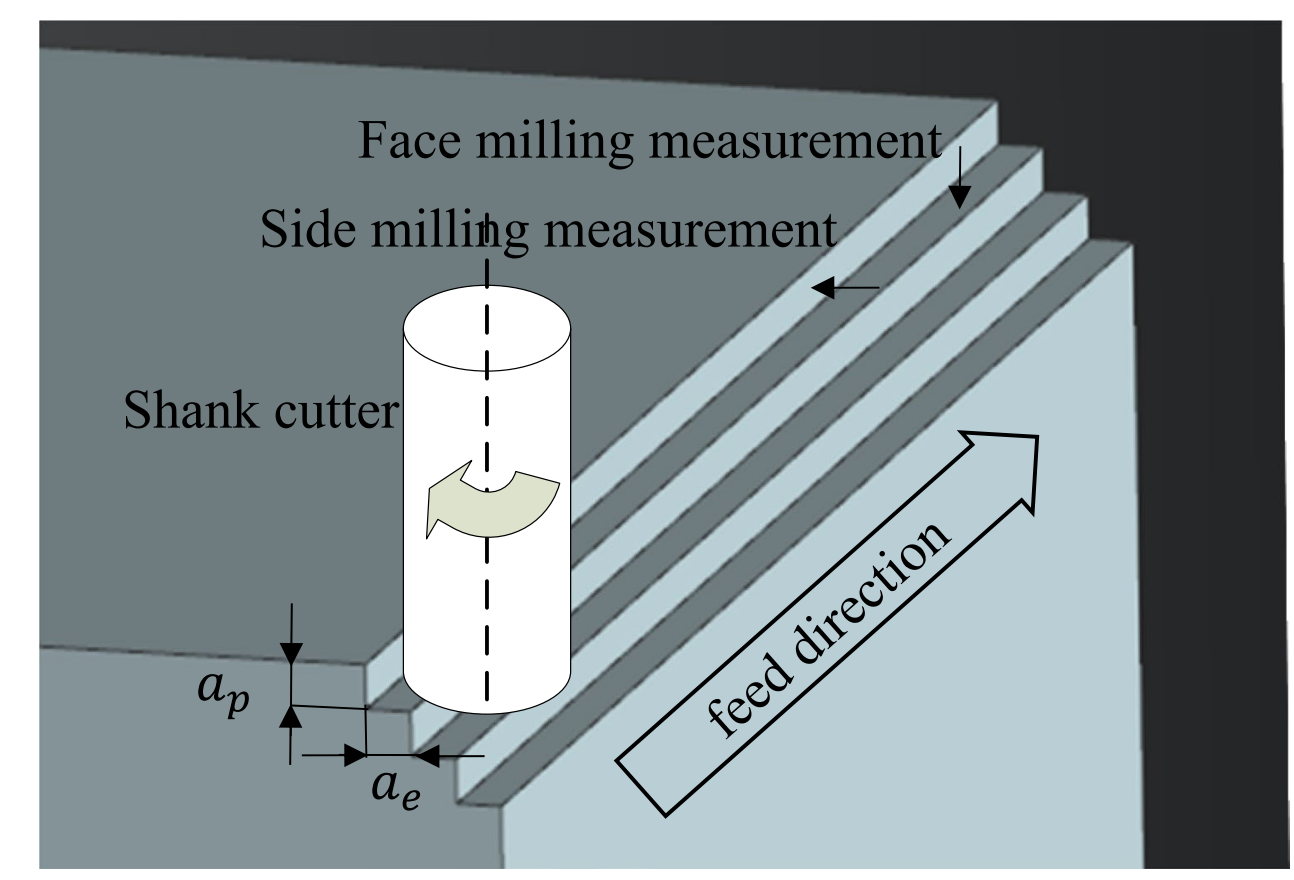

\begin{tabular}{lllllll}
\hline & $\begin{array}{l}\text { Cutting depth Cutting width } \\
a_{p}[\mathrm{~mm}]\end{array}$ & $\begin{array}{l}\text { Cutting speed } \\
a_{e}[\mathrm{~mm}]\end{array}$ & $\begin{array}{l}\text { Feed per } \\
V_{c}[\mathrm{~m} / \mathrm{min}]\end{array}$ & $\begin{array}{l}\text { Spindle } \\
\text { tooth } f_{c}[\mathrm{~mm}]\end{array}$ & $\begin{array}{l}\text { Feed rate } \\
\text { speed } n \\
{[\mathrm{rpm}]}\end{array}$ & $\begin{array}{l}v_{f}[\mathrm{~mm} / \\
\text { min }]\end{array}$ \\
\hline Face milling & $3,2,1$ & 2.5 & 90 & 0.035 & 2865 & 401 \\
Side milling & $3,2,1$ & 1 & 72 & 0.035 & 2292 & 321 \\
\hline
\end{tabular}

Table 1. Parameter of the milling experiment 
measurement system is based on the optical stereo camera principle and has a point spacing of $0.08 \mathrm{~mm}$.

In the torsional shear-off experiment a digital wrench adapter (BikeMaster) for the torque measurement was used, as shown in Fig. 12a. Moreover, a confocal laser scanning microscope (Keyence VK-X $200 \mathrm{~K}$ ) was used to measure the height of the residual material after the shear off. Figure $12 \mathrm{~b}$ shows the exemplary residual material of the stepwise and (c) continuous predefined notches.

\section{Results}

\subsection{Compliance experiment}

This section describes the test setup and methods used to analyze the compliance. Figure 13 shows the different displacement conditions of the bolts during the displacement measurements, including the maximum displacement $x_{\max }$ and remaining displacement $\mathrm{x}_{\mathrm{r}}$.
Figure 14 shows the compliance $S=\frac{x_{\max }}{F}$ for the symmetric load case. The remaining displacement $\mathrm{x}_{\mathrm{r}}$ was primarily based on two effects: the structural plastic deformation of the LPBF part and the slippage in the fixture. For precise finishing, high tolerances and therefore low compliance and low displacements are required. For the symmetric load case, measurements were performed at loads of $250 \mathrm{~N}, 500 \mathrm{~N}$, $750 \mathrm{~N}, 1000 \mathrm{~N}, 1250 \mathrm{~N}$, and $1500 \mathrm{~N}$ was applied. The global maximum compliance of $0.052 \mu \mathrm{m} / \mathrm{N}$ and global maximum remaining displacement of $53.5 \mu \mathrm{m}$ occurred for sample 2 , with a stepwise and predefined notch, vertical shaft, and round interface. The lowest values occurred for sample 3 , with a continuous and predefined notch, an inclined shaft, and a round interface. Considering the $250 \mathrm{~N}$ force, which is required for precise finishing, a maximum compliance of $0.035 \mu \mathrm{m} / \mathrm{N}$ and a maximum remaining displacement of $0.85 \mu \mathrm{m}$ were measured.

Figure 15 shows the asymmetric compliance $\mathrm{S}$ and the remaining displacement $\mathrm{x}_{\mathrm{r}}$, which represents the worst-case
Fig. 12 a Shear-off experiment; $\mathbf{b}$ residual material after shearing-off the stepwise predefined notch; $\mathbf{c}$ continuous predefined notch
Fig. 13 Displacement states of the bolts during the behavior experiment
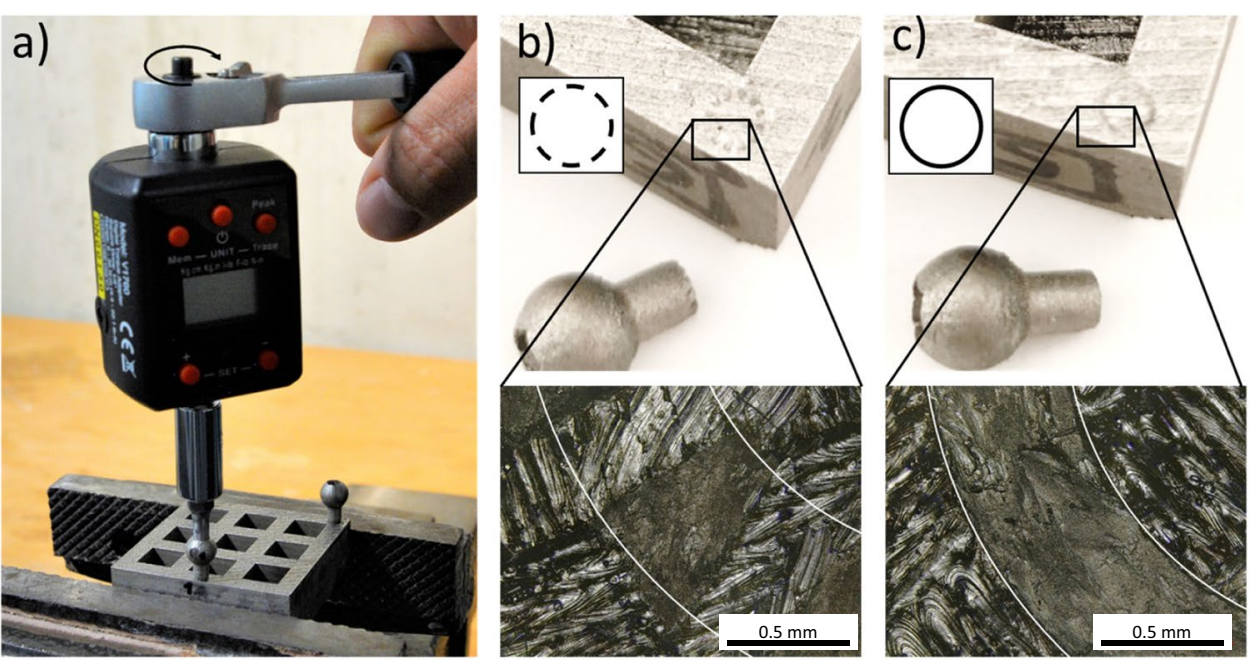

a) Before load introduction

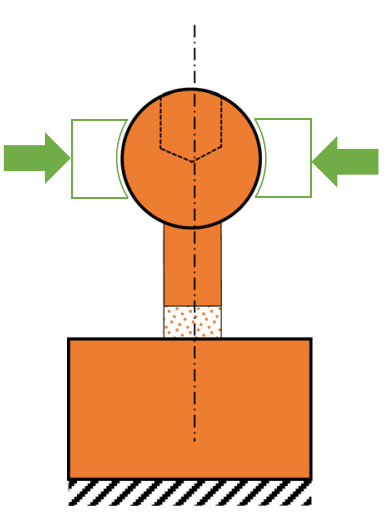

b) Maximum deformation

c) Remaining deformation $x_{r}$ $x_{\max }$ during load introduction after load introduction

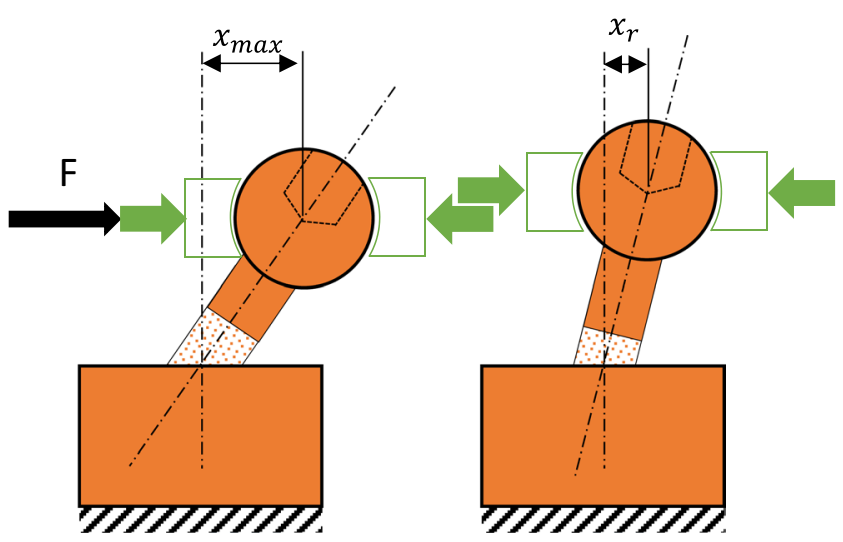




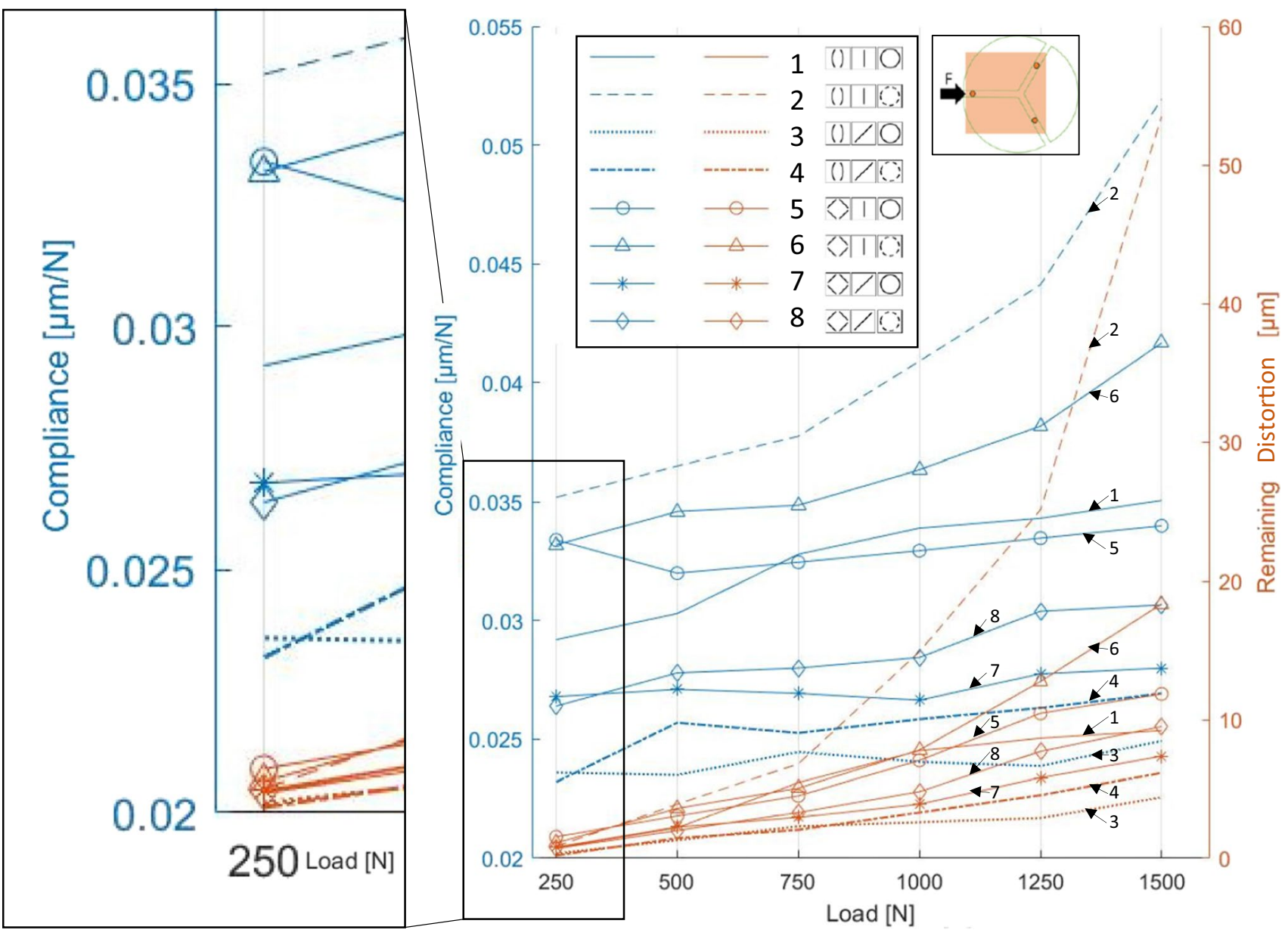

Fig. 14 Compliance (blue) and remaining displacement (orange) of the symmetric load cases for different examined bolt concepts

scenario as the highest load occurs on one bolt. For the asymmetric load case, measurements were performed at loads of $250 \mathrm{~N}, 500 \mathrm{~N}, 750 \mathrm{~N}$, and $1000 \mathrm{~N}$ was applied. Similar to the symmetric measurements, sample $2 \mathrm{had}$ a maximum global compliance of $0.112 \mu \mathrm{m} / \mathrm{N}$ and maximum global remaining displacement of $67.4 \mu \mathrm{m}$. However, sample 3 had the lowest compliance and remaining displacement values. In the $250 \mathrm{~N}$ load case, a maximum compliance of $0.05 \mu \mathrm{m} / \mathrm{N}$ was measured, which was higher than that recorded in the symmetric load case. Moreover, a maximum remaining displacement of $1.1 \mu \mathrm{m}$ was measured.

To obtain a deeper insight into the effect of different design elements and their interactions, a statistical analysis of the compliance was performed. To cover a wide load range, average values between 250 and $1000 \mathrm{~N}$ were measured to compare the stiffness values of different load cases. Table 2 shows the $p$ values for the symmetric and asymmetric load cases with a confidence level of $95 \%$. The influential factors of the shaft had statistically significant effects in the symmetric and asymmetric load cases. Further, the predefined notch had a significant effect on the asymmetric compliance load case.

Figures 16 and 17 show the main effect diagrams for the symmetric and asymmetric stiffness, respectively, the steeper the lines, the larger is the effect.

Figures 18 and 19 show the interaction diagrams for symmetric and asymmetric stiffness. The more parallel the lines, the lower are the interactions between the factors. As shown in the figures, a large interaction occurs between the shaft and interface after the asymmetric load introduction. The inclined bolts indicate a lower compliance with the round interfaces in the symmetric and asymmetric load cases. Furthermore, a minor interaction occurred in the interaction between the predefined notch and interface, as well as between the notch and shaft, in the symmetric and asymmetric load cases.

\subsection{Compliance simulation}

For all test samples, the compliance for the relevant $250 \mathrm{~N}$ was simulated using the FEA model to compare the results 


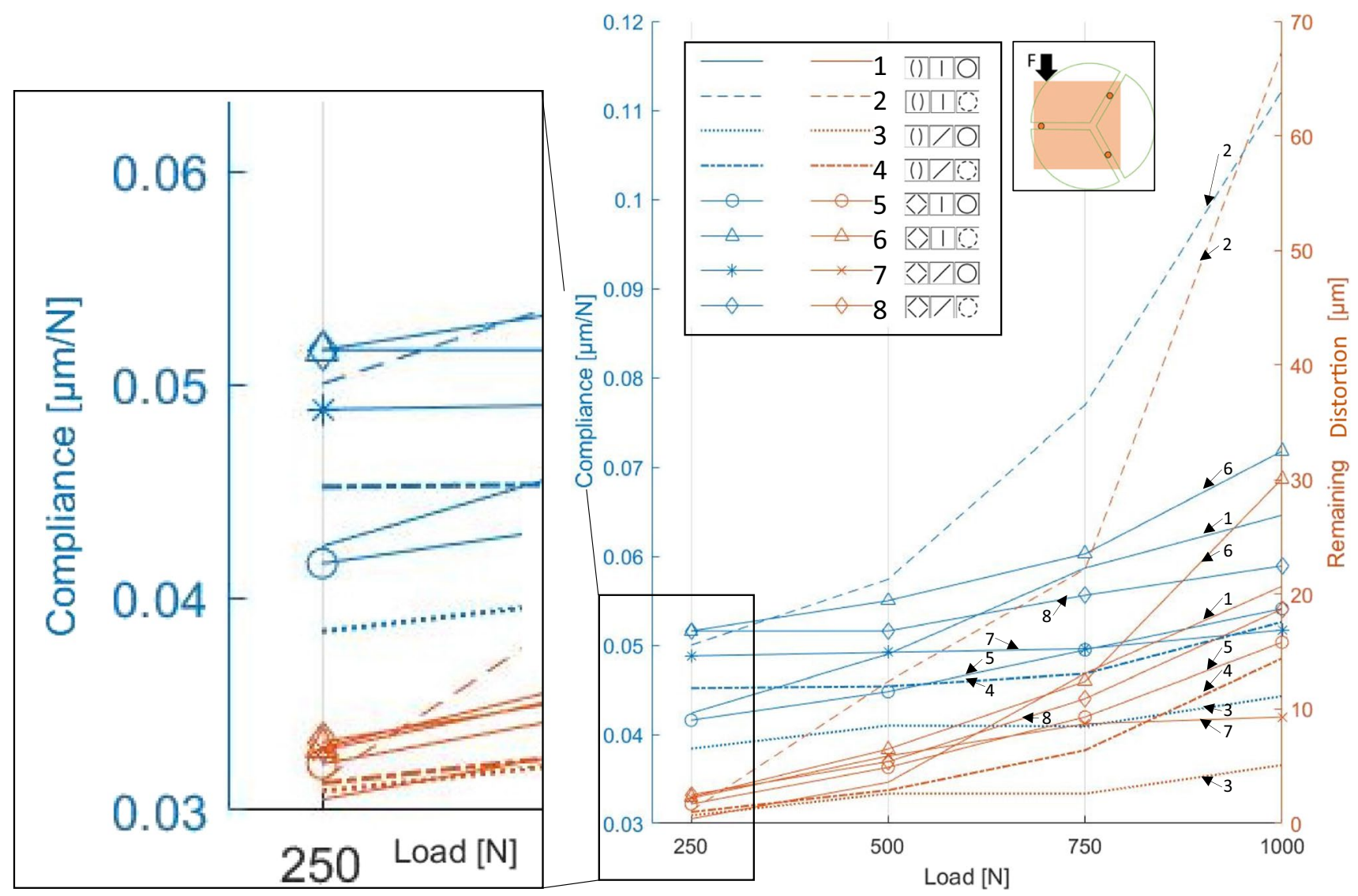

Fig. 15 Compliance (blue) and remaining displacement (orange) of the asymmetric load cases for different examined bolt concepts

with the the experimental ones. Figure 20 shows the total displacement and v. Mises stress, where a fixed boundary condition leads to lower displacement and lower stresses as compared to the stick-slip boundary condition.

Figures 21 and 22 compare the the compliance of the stick-slip boundary condition and fixed boundary condition for the symmetric and asymmetric loadcases, respectively. The simulation and experimental results show an approximated trend for all cases. When applying a simulation under the fixed boundary condition, the compliance with the stick-slip effect was reduced by $49.3 \%$ on average for the symmetrical load introduction and $43.8 \%$ for the asymmetric load introduction. Consequently,

Table $2 p$ values for the symmetric and asymmetric load case for the average compliance values between 205 and $1000 \mathrm{~N}$

\begin{tabular}{lll}
\hline & Symmetric load case & $\begin{array}{l}\text { Asymmet- } \\
\text { ric load } \\
\text { case }\end{array}$ \\
\hline Interface & 0.049 & 0.046 \\
Shaft & 0.029 & 0.071 \\
Notch & 0.025 & 0.229 \\
\hline
\end{tabular}

approximately half of the remaining displacement was most possibly by the stick-slip effect of the fixture. Table 3 shows the deviation between compliance measurements and compliance simulations.

\section{Milling}

The milling experiments were conducted for three cutting depths $a_{p}$ using both face and side milling. The average surface roughness $\mathrm{Ra}$ was measured, and its values are listed in Table 4. As a reference, a rigid part was clamped in a rigid standard clamping system with a parallel jaw.

The measured Ra values of the milling results were at $95 \%$ confidence level. Therefore, no statistically significant effects of the different bolt designs were observed. The face milling roughness showed a maximum $\mathrm{Ra}$ value of 0.88 , and the side milling showed a maximum Ra value of 1.42. Compared to the reference for face milling, the surface roughness with the three-jaw clamping system had the same Ra value. For the side milling, the roughness was increased by $13 \%$. 
Fig. 16 Main effect diagrams for symmetric stiffness

Fig. 17 Main effect diagrams for asymmetric stiffness

Fig. 18 Interaction diagrams for symmetric stiffness
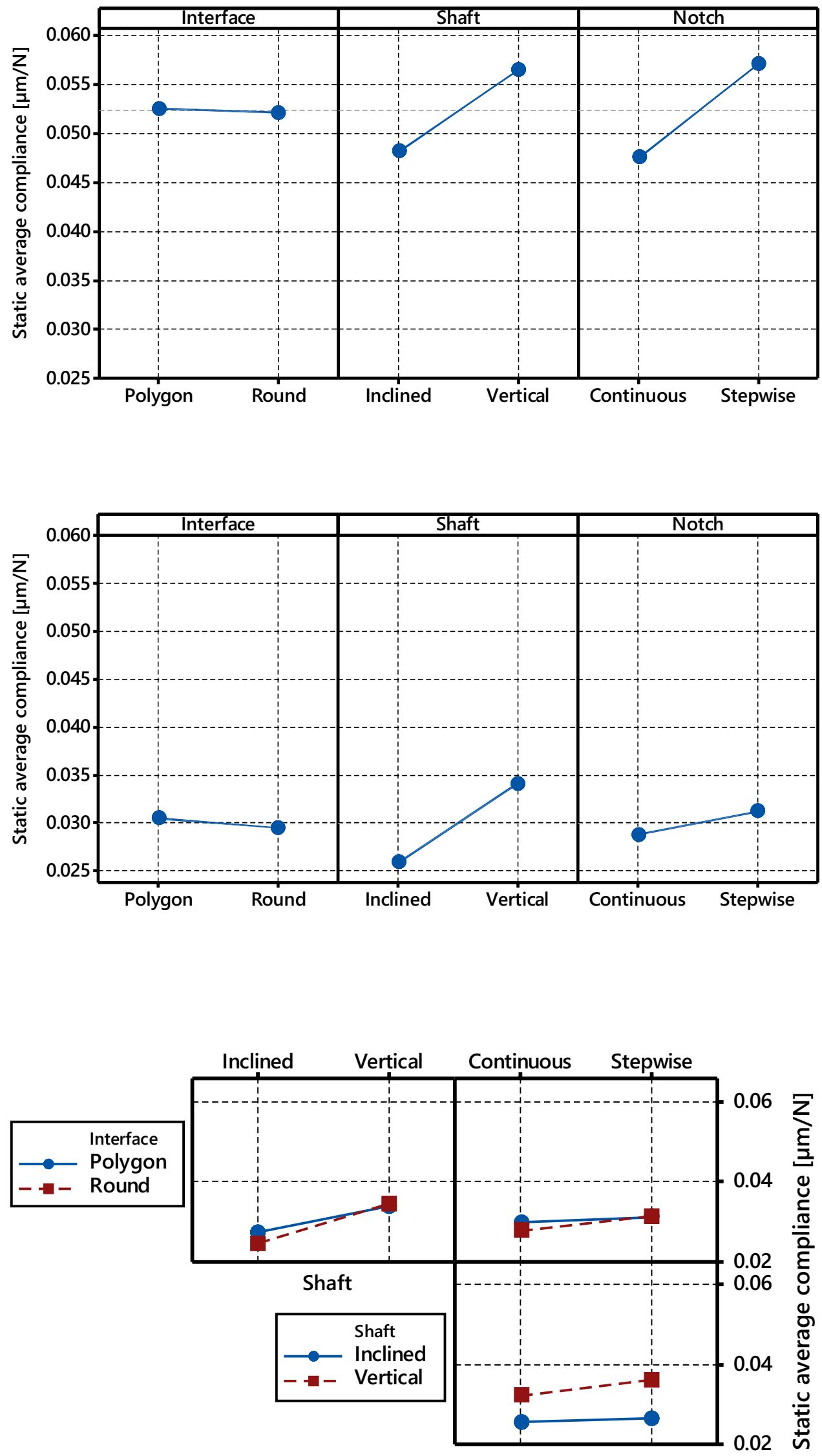

Notch 
Fig. 19 Interaction diagrams for the asymmetric stiffness

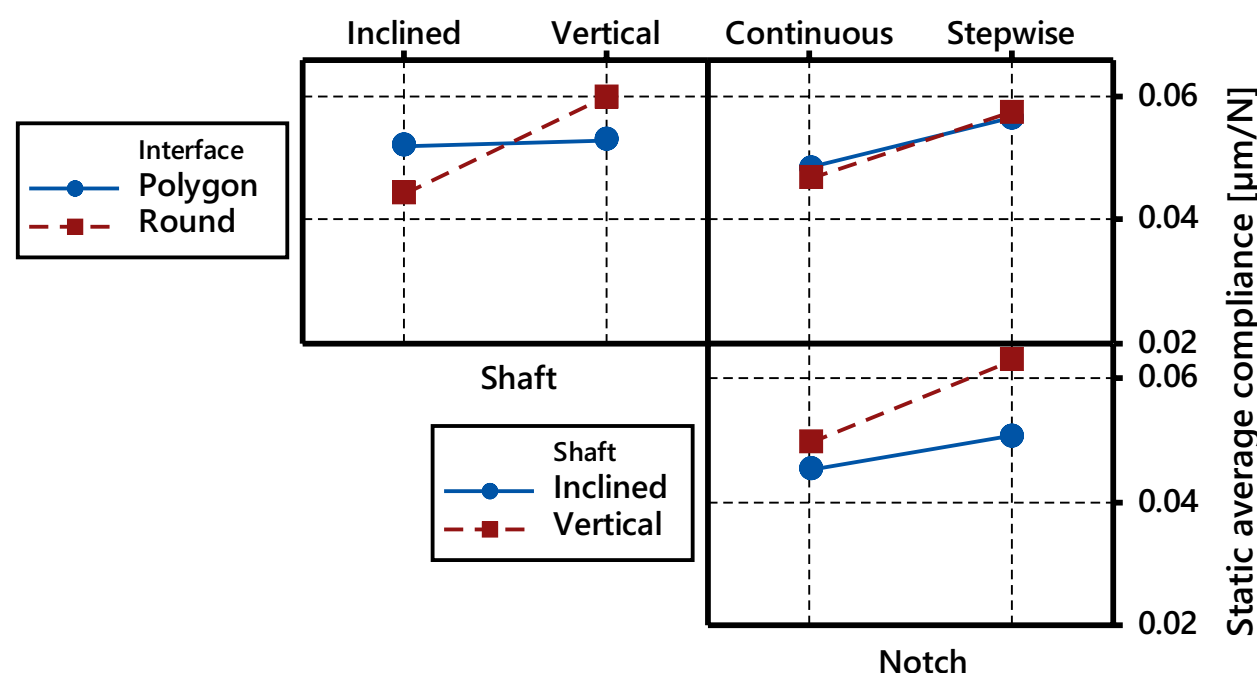

Notch
Fig. 20 Total displacement and v. Mises stress, exemplary sample 2 for a symmetric load case

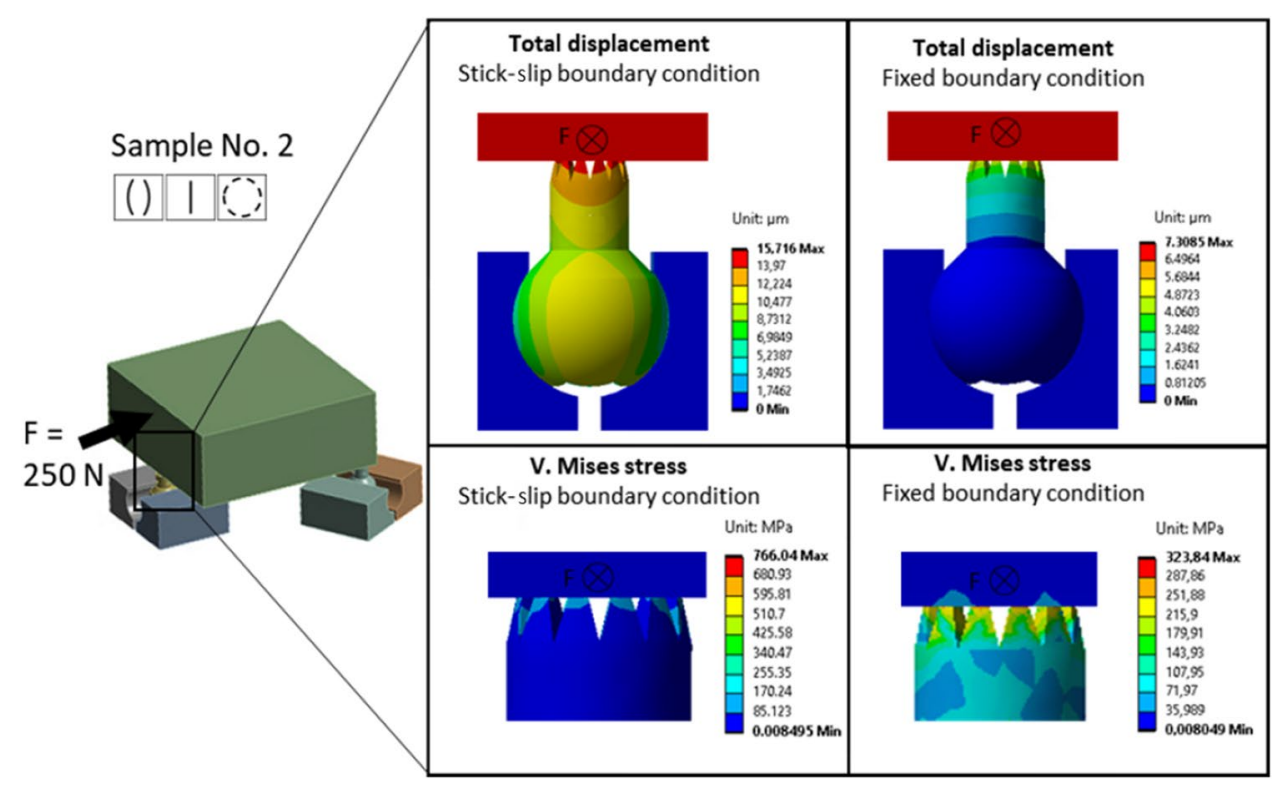

Figure 23 shows the residual materials of the different samples. The overall results in Table 5 show that the removed bolts have very little residual heights with a maximal value of $0.067 \mathrm{~mm}$.

\section{Case studies}

\subsection{Inspection robot}

The bolts were integrated in the LPBF manufactured housing of an inspection robot to demonstrate the robustness of the vertical shaft design. This robot inspects pipes with a phased-array ultrasonic sensor for quality assurance of welds and corrosion mapping. The housing was mass-customized 
Fig. 21 Simulation under stick-slip boundary condition, simulation under fixed boundary condition, and experimental results for the symmetric load case at $250 \mathrm{~N}$

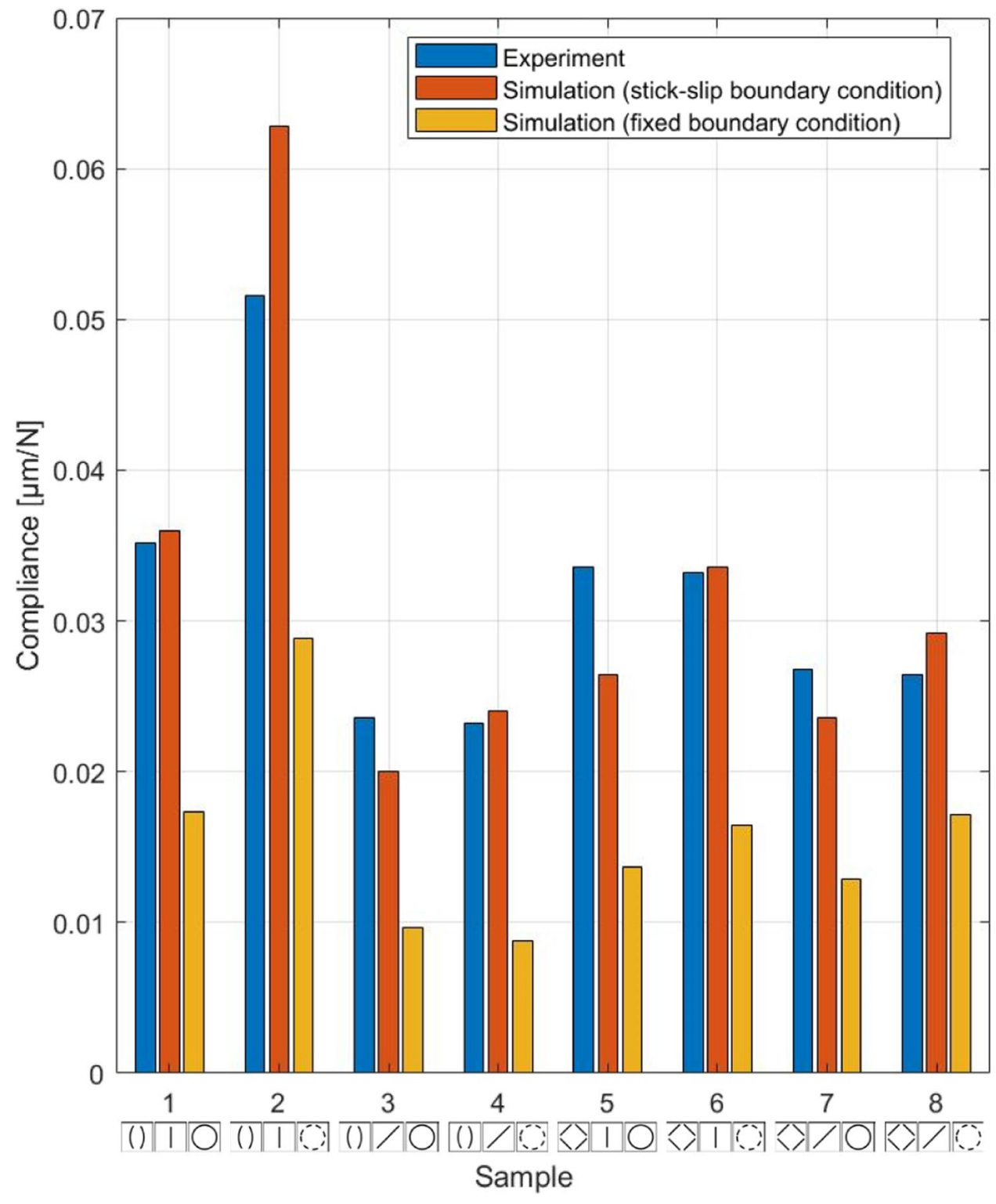

to fit different pipe diameters within tight installation spaces. The robot assembly comprised several movable elements, which required high-precision bearing seats in the housing.

The housing of the robot was already additively manufactured in series production. The primary challenge of the current AM design was the cost-intensive post-processing because of several re-clampings within the machining process. Thus, the primary aim of this case study was to demonstrate that the bolts integrated in the new part enabled machining from five sides without re-clamping.

Three bolts were positioned on the non-functional surfaces. The limited space in the fixed housing design allowed only vertical bolts. The housing geometry limited the bolt diameter. Two of the bolts had a diameter of $4 \mathrm{~mm}$. However, the third bolt had a diameter of $3.7 \mathrm{~mm}$. The bolts with a stepwise predefined notch design were integrated in the housing to validate the worst-case scenario during milling. The entire housing was printed on a rolled metallic preform sheet, which was fixed with nine countersunk-head screws on the machine base plate. After the process, the sheet metal could be simply removed by releasing the screws, thus avoiding the sawing and erosion processes involved in the part removal. An offset of $0.3 \mathrm{~mm}$ was added to all surfaces that required milling. Figure 24 shows the main manufacturing steps involved in inspection robotic housing.

Figure 25 shows the frequency response function (FRF) and point measurement setup, including the hammer and the measuring point of the acceleration. The FRF of the housing shows a single dominant natural frequency peak at $815 \mathrm{~Hz}$.

Figure 26 shows the detailed production process of the housing starting from LPBF to the finished part. The entire machining operation was performed without any 
Fig. 22 Simulation under stick-slip boundary condition, simulation under fixed boundary condition, and experimental results for the asymmetric load case at $250 \mathrm{~N}$

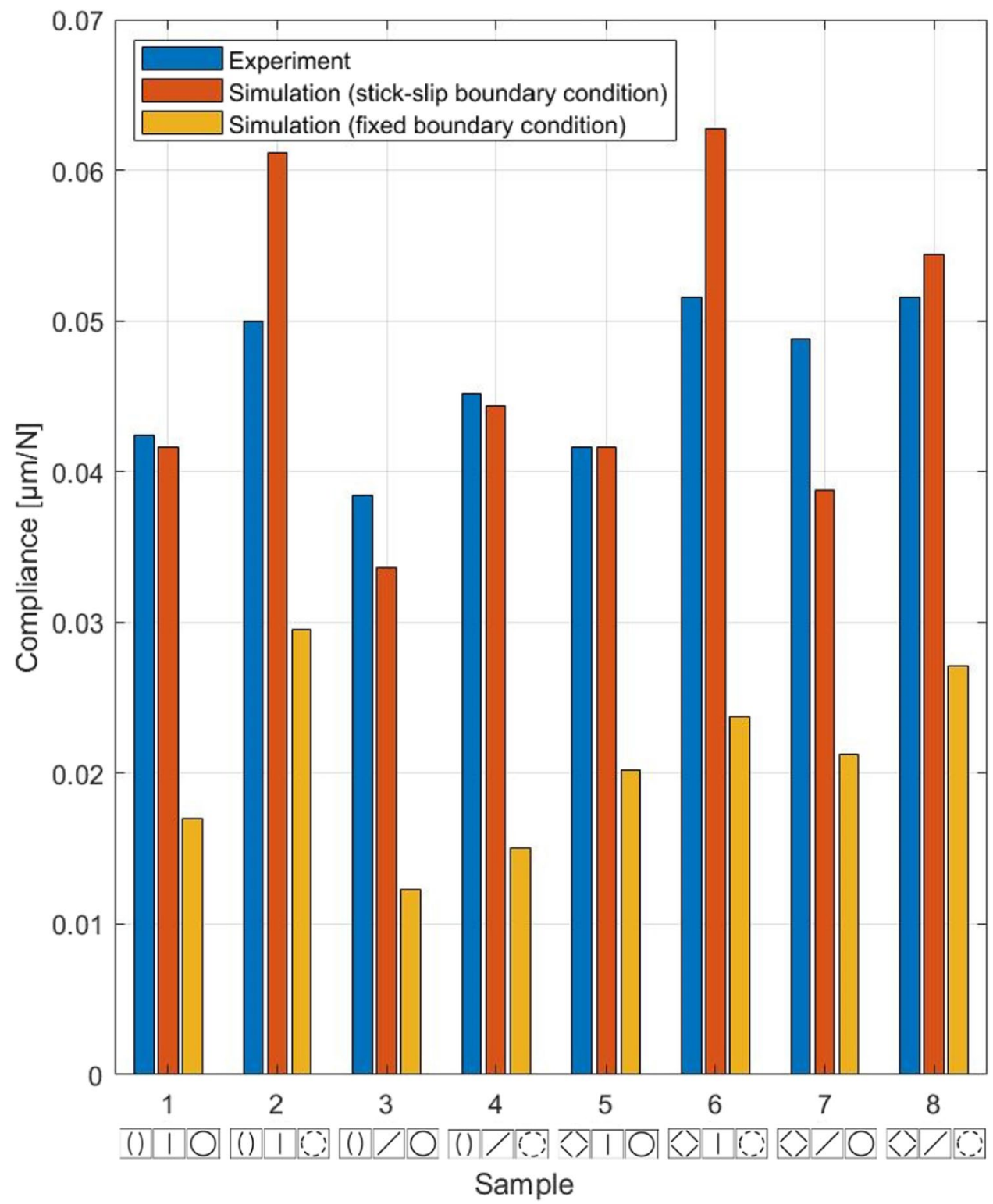

re-clamping. During the milling process, the overhanging sheet metal was removed by milling between steps (c) and (d), as well as further 19 surfaces on the part were machined with three different tools. Figure $26 f$ shows the machined surfaces marked in yellow. The used bolts were printed on a curved surface with a radius of $10 \mathrm{~mm}$ and are shown in Fig. 26g. During the milling process, no chatter was observed, and the maximum measured Ra was $0.9 \mu \mathrm{m}$. The
Table 3 Compliance deviation between measurement and simulations

\begin{tabular}{|c|c|c|c|c|c|c|c|c|}
\hline & Sample & Sample & Sample & Sample & Sample & e Sample & Sample & Sample \\
\hline & 1 & 2 & 3 & 4 & 5 & 6 & 7 & 8 \\
\hline $\begin{array}{l}\text { Compliance deviation between simulation } \\
\text { (stick slip boundary condition) and } \\
\text { experiment for the symmetric load case [\%] }\end{array}$ & 2.3 & 21.7 & 15.3 & 3.4 & 21.4 & 1.2 & 11.9 & 10.6 \\
\hline $\begin{array}{l}\text { Compliance deviation between simulation } \\
\text { (stick slip boundary condition) and } \\
\text { experiment for the asymmetric load case [\%] }\end{array}$ & 1.9 & 22.4 & 12.5 & 1.8 & 0.0 & 21.7 & 20.5 & 5.4 \\
\hline $\begin{array}{l}\text { Measurement shear off Compliance } \\
\text { deviation between simulation (fixed }\end{array}$ & 50.7 & 44.0 & 58.9 & 62.0 & 59.2 & 50.3 & 51.8 & 35.0 \\
\hline $\begin{array}{l}\text { boundary condition) and experiment for the } \\
\text { symmetric load case }[\%]\end{array}$ & & & & & & & & \\
\hline $\begin{array}{c}\begin{array}{c}\text { Measured shear off Compliance deviation } \\
\text { between simulation (fixed boundary } \\
\text { condition) and experiment average for the } \\
\text { asymmetric load case [\%] }\end{array} \\
\end{array}$ & 59.9 & 40.8 & 68.1 & 66.7 & 51.3 & 53.9 & 56.5 & 47.4 \\
\hline
\end{tabular}


Table 4 . Ra results for the milling experiment

\begin{tabular}{|c|c|c|c|c|c|c|c|c|c|c|}
\hline & $\begin{array}{l}a_{p} \\
{[\mathrm{~mm}]}\end{array}$ & $\begin{array}{l}\text { Reference: } \\
\text { Rigid } \\
\text { clamping }\end{array}$ & 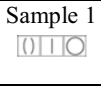 & $\begin{array}{c}\text { Sample } 2 \\
\square(1) \sigma\end{array}$ & $\begin{array}{c}\text { Sample } 3 \\
(0)<0\end{array}$ & $\begin{array}{c}\text { Sample } 4 \\
1(1)\end{array}$ & $\begin{array}{c}\text { Sample } 5 \\
\text { Kताण }\end{array}$ & $\begin{array}{c}\text { Sample } 6 \\
\text { Kत्र十O }\end{array}$ & $\begin{array}{c}\text { Sample } 7 \\
\qquad>100\end{array}$ & $\begin{array}{c}\text { Sample } 8 \\
k>>\end{array}$ \\
\hline \multirow[t]{3}{*}{ Face milling Ra $[\mu \mathrm{m}]$} & 3 & 1.02 & 0.77 & 0.76 & 0.76 & 0.90 & 0.83 & 0.92 & 0.99 & 0.71 \\
\hline & 2 & 0.84 & 0.67 & 0.70 & 0.72 & 0.80 & 0.71 & 0.88 & 0.71 & 0.71 \\
\hline & 1 & 0.78 & 0.72 & 0.82 & 0.70 & 0.80 & 0.81 & 0.84 & 0.83 & 0.81 \\
\hline \multicolumn{2}{|l|}{ Average Ra $[\mu \mathrm{m}]$} & 0.88 & 0.72 & 0.76 & 0.73 & 0.83 & 0.79 & 0.88 & 0.84 & 0.74 \\
\hline \multicolumn{2}{|c|}{ Percentage deviation from reference } & 0 & -18 & -13 & -17 & -5 & -11 & 0 & -4 & -6 \\
\hline \multirow[t]{3}{*}{ Side milling Ra $[\mu \mathrm{m}]$} & 3 & 1.40 & 1.49 & 1.37 & 1.34 & 1.26 & 1.46 & 1.40 & 1.44 & 1.46 \\
\hline & 2 & 1.14 & 1.39 & 1.37 & 1.33 & 1.28 & 1.30 & 1.38 & 1.30 & 1.33 \\
\hline & 1 & 1.21 & 1.38 & 1.36 & 1.30 & 1.46 & 1.45 & 1.41 & 1.39 & 1.40 \\
\hline \multicolumn{2}{|l|}{ Average Ra $[\mu \mathrm{m}]$} & 1.25 & 1.42 & 1.36 & 1.32 & 1.33 & 1.41 & 1.40 & 1.38 & 1.39 \\
\hline \multicolumn{2}{|c|}{ Percentage deviation from reference } & 0 & 13 & 9 & 6 & 7 & 12 & 12 & 10 & 11 \\
\hline
\end{tabular}

bolts were easily sheared off using a wrench, and no material residuals were left on the parts.

Figure 27 shows the deviation between the 3D modeled part and the AM part, including a hybrid metallic sheet. Figure 27a shows the part after being removed from the base plate. Strong thermal deformations occurred on the sheet. Certain local LPBF process-related deformations occurred on the AM part. Figure $27 \mathrm{~b}$ shows the final part at the clamped position. The maximum deviation caused by the bolts was $0.3 \mathrm{~mm}$.

\subsection{Aircraft bracket}

To demonstrate the practical applicability of the inclined shafts in the LPBF build direction, the part-integrated bolts were applied to an optimized topology aircraft bracket.

The aircraft bracket had several screw connections that required milling to finish the interfaces. However, a big challenge within the process chain of aircraft brackets is the removal of the support structures and milling of the functional surfaces. Thus, an offset of $0.3 \mathrm{~mm}$ was added to all surfaces that required milling. Figure 28 shows the primary process steps involved in the aerospace bracket.
The aircraft bracket is a topology optimized structure for a specific load case. For other load cases, such as clamping using two jaws, the design was fragile and required additional materials. Therefore, the use of bolts is ideal in such processes because it does not induce additional stress. The ideal build direction, which requires minimal support, is plotted in Fig. 28a.

Figure 29a shows the monolithic bolt design with a functional ball interface at the end. The inclined orientation of the shaft requires support structures for the clamping balls. Such support structures require to be manually removed prior to the machining process. Thus, to achieve completely automated machining, it is necessary to avoid such support structures. The proposed solution is to separate the shaft and functional ball into two parts. On top of the shaft, a separately reusable LPBF-produced cap with two wings is added for clamping of the bolts, as shown in Fig. 29b. The cap has an interlocking snap-fit connection with the shaft and can be manually added or using a robot. Furthermore, the wings ensure that the cap is ideally oriented between the jaws.

The bolt design for the cap has a shaft with an outside hexagonal design for a wrench to shear off the bolts. The estimated shear-off torque is between 3.3 and $4.7 \mathrm{Nm}$ depending on the connection angle to the solid part. The
Table 5 . Results of the shearoff torque and shear off height

\begin{tabular}{|c|c|c|c|c|c|c|c|c|}
\hline & Sample & Sample & Sample & Sample & Sample & Sample & Sample & $\begin{array}{c}\text { Sample } \\
8\end{array}$ \\
\hline & \begin{tabular}{|l|l} 
& 1 \\
& 1 \\
\end{tabular} & 010 & $10^{3} / 0$ & 40 & K $\frac{5}{1} \mathrm{O}$ & का? & & $k><$ \\
\hline 1. Measurement shear off torque [Nm] & 5.6 & 2.7 & 6.8 & 3.9 & 5.6 & 2.6 & 7.1 & 4.1 \\
\hline 2. Measurement shear off torque [Nm] & 5.3 & 2.9 & 7.2 & 3.9 & 5.4 & 2.9 & 6.2 & 3.8 \\
\hline 3. Measurement shear off torque [Nm] & 5.4 & 2.6 & 5.2 & 4.1 & 5.3 & 2.8 & 8 & 4.2 \\
\hline Measured shear off torque average [Nm] & 5.4 & 2.7 & 6.4 & 4.0 & 5.4 & 2.8 & 7.1 & 4.0 \\
\hline Simulated shear off torque [Nm] & 4.6 & 3.1 & 6.6 & 4.3 & 4.6 & 3.1 & 6.6 & 4.3 \\
\hline $\begin{array}{c}\text { Shear off torque deviation between } \\
\text { simulation and measurement [\%] }\end{array}$ & 17.4 & 12.9 & 3.0 & 7.0 & 17.4 & 9.7 & 7.6 & 7.0 \\
\hline 1. Measurement shear off height [mm] & 0.026 & 0.029 & 0.026 & 0.03 & 0.016 & 0.014 & 0.034 & 0.05 \\
\hline 2. Measurement shear off height [mm] & 0.023 & 0.033 & 0.024 & 0.029 & 0.02 & 0.009 & 0.038 & 0.09 \\
\hline 3. Measurement shear off height [mm] & 0.024 & 0.032 & 0.036 & 0.026 & 0.021 & 0.009 & 0.025 & 0.06 \\
\hline Measurement shear off height average [mm] & 0.024 & 0.031 & 0.029 & 0.028 & 0.019 & 0.011 & 0.032 & 0.067 \\
\hline
\end{tabular}


shaft includes the same predefined notches for the cap design as those for the monolithic design.

The effects of the monolithic and cap design on the FRF and milling process were investigated. Figure 30 shows the FRF, position of the induced hammer force, and measurement location of both the monolithic and cap designs. The measurement location was carefully selected such that it can coincide with a critical position at which high vibrations are expected. Both designs had a dominant natural frequency peak at $818 \mathrm{~Hz}$. At this frequency, the compliance of the monolithic design was significantly higher than that of the cap design. It is assumed that the contact between the shaft and cap damped the vibrations. Another dominant peak occurred at $627 \mathrm{~Hz}$ with the monolithic design. At higher frequencies, no dominant natural frequencies occurred.

Figure 31 shows the surface roughness for both design variants after milling. Figure $31 \mathrm{c}$ and $\mathrm{f}$, and to some extent Fig. $31 \mathrm{~b}$ and e, showed chatter marks on the bracket, which were formed because of the thin walls at this position which could not supported by the bolts. Despite the chatter marks, the surface roughness was not substantially increased. The milled surfaces of the cap showed slightly lower roughness than the monolithic designs, which corresponded to the FRF results.

The brackets were 3D-scanned and compared with the CAD model to investigate the accuracies of the LPBF part and the milling process. Figures 32 and 33 show the aircraft bracket from two different perspectives. Figure 32 focuses on the bolt accuracy, while Fig. 33 focuses on the milling surface, which is a functional surface, requiring high accuracy.

Figure $32 \mathrm{a}$ and $\mathrm{b}$ show the deviations between the LPBF parts and CAD part for the monolithic design and cap design, respectively. The bolt interfaces had a maximum deviation of $0.1 \mathrm{~mm}$. Certain regions showed higher deviations because of the local inaccuracies of the LPBF process such as dross formation on down-skin surfaces and thermal deformation induced by residual stresses of the LPBF process [29, 31].

Figure 33 shows the deviation in the aircraft bracket between the 3D model and AM parts. Figure 33a shows the monolithic design, and Fig. 33b shows the cap design. The maximum deviation caused by the inaccuracy of the bolts was $0.3 \mathrm{~mm}$.

Figure 34 shows the detailed manufacturing process of the aircraft bracket using the monolithic and cap designs, and Fig. 34f highlights the milling surfaces. The milling process machines nine surfaces with three tools, involving a fully automated support removal process. All steps were performed without any re-clamping.

\subsection{Effect of bolts on build time and material volume}

The integration of bolts requires additional build time, material and, in some cases, builds height in the LPBF process. The volume of each bolt depends on its length, diameter, and ball type. The height of the build increases only when the bolts exceed the top of the part and require additional layers in the LPBF process. Both the additional volume and layers increase the build time of a part. Table 6 lists the effect of the integrated bolts on the different parts used in this study. Each part was manufactured in an individual build job without other parts on the build platform. The parts represented the range of integrated bolts and demonstrated the impact of the bolts on the build height, volume, and time.

\section{Discussion and outlook}

This paper proposes new interfaces in the form of bolts for handling and clamping AM parts. The experimental results of bolts, including the milling experiments, exhibited robustness and practical applicability, and achieved a surface quality comparable to that of traditional clamping systems.

\subsection{Bolts}

The experiments demonstrated acceptable compliance and displacement, which enabled precision finishing. A global maximum compliance of $0.112 \mu \mathrm{m} / \mathrm{N}$ and a global max displacement of $67.4 \mu \mathrm{m}$ occurred in the asymmetric load case at $1000 \mathrm{~N}$. As for the symmetric compliance, the values were significantly lower even at a load of $1500 \mathrm{~N}$. At a representative load of $250 \mathrm{~N}$ for milling, the maximum compliance was $0.05 \mu \mathrm{m} / \mathrm{N}$, and the maximum remaining displacement was $1.1 \mu \mathrm{m}$ for the asymmetric load case. The symmetric load case was significantly lower and the maximum values always occurred on sample 2 with a stepwise predefined notch, vertical shaft, and round interface.

The compliance experiment showed a dominant main effect on the average compliance of the shaft and the predefined notch on the bolt. However, the chuck interface had no effect. The inclined shaft showed a stiffer average compliance because of the following reasons: (i) A more direct force transmission from the AM part to the chuck was provided; thus, a lower stress and deformation occurred at the notch. (ii) Moreover, the cross-section of the inclined notch was higher than that of the vertical notch, leading to lower stress and compliance. (iii) Finally, the lever was $0.9 \mathrm{~mm}$ shorter, leading to lower rotational moment. An interaction of factors responsible for the average compliance was observed between the shaft orientation and chuck interface. This was caused by the rotational moment and different force 
Table 6. Additional build time and material

\begin{tabular}{|c|c|c|c|c|c|c|}
\hline & & \multicolumn{2}{|c|}{ Aircraft bracket } & \multirow[t]{2}{*}{ Robotic Housing } & \multicolumn{2}{|c|}{ Test sample } \\
\hline & & Monolithic & Cap design & & Straight & Inclined \\
\hline \multirow[t]{4}{*}{ Build height } & Total build height [mm] & 75,50 & 72.50 & 22.40 & 36.40 & 36.40 \\
\hline & Part and support build height $[\mathrm{mm}]$ & 68.30 & 68.30 & 9.10 & 23.90 & 23.90 \\
\hline & Bolt build height [mm] & 7.20 & 4.20 & 13.30 & 12.50 & 12.50 \\
\hline & Additional bolts' build height & $9.54 \%$ & $5.79 \%$ & $59.38 \%$ & $34.34 \%$ & $34.34 \%$ \\
\hline \multirow[t]{4}{*}{ Material volume } & Total material volume $\left[\mathrm{cm}^{3}\right]$ & 11.76 & 11.44 & 5.38 & 37.66 & 37.69 \\
\hline & Part and support volume $\left[\mathrm{cm}^{3}\right]$ & 11.00 & 11.00 & 4.44 & 36.90 & 36.90 \\
\hline & Bolt volume $\left[\mathrm{cm}^{3}\right]$ & 0.76 & 0.44 & 0.94 & 0.76 & 0.79 \\
\hline & Additional bolts' volume & $6.91 \%$ & $4.00 \%$ & $21.17 \%$ & $2.05 \%$ & $2.14 \%$ \\
\hline \multicolumn{7}{|l|}{ Build } \\
\hline \multirow[t]{4}{*}{ Time } & Total build time $[\mathrm{h}]$ & 8.75 & 8.48 & 3.69 & 11.76 & 11.82 \\
\hline & Part and support build time $[\mathrm{h}]$ & 8.12 & 8.12 & 1.61 & 10.78 & 10.78 \\
\hline & Bolt build time [h] & 0.63 & 0.36 & 2.08 & 0.98 & 1.08 \\
\hline & Additional bolts' build time & $7.76 \%$ & $4.43 \%$ & $129.19 \%$ & $9.09 \%$ & $10.01 \%$ \\
\hline
\end{tabular}

transitions of the inclined and vertical shafts. The polygon interface was more beneficial for the vertical shafts because of the form closure, and the round interface was more beneficial for the inclined shafts because of the reduced surface stresses and lower remaining displacements. The continuous predefined notch had a positive effect on the compliance because of a lower stress accumulation. The stress accumulation in the stepwise predefined notch was higher because of the additional geometrical notches.

The static force was simulated to validate the relevant displacement in the experiment and investigate the friction of the fixture. An approximate trend between the simulation and experimental results was observed, as plotted in Figs. 21 and 22. The main reason for the inaccuracy is the approximation of the friction between the chucks and the balls. When applying a simulation under the fixed boundary condition, the compliance with the stick-slip effect was reduced by approximately $50 \%$.

The milling surface roughness, which has a max Ra of $0.88 \mu \mathrm{m}$ with face milling, is in a similar range compared to the results obtained by Fortunato et al. [29] for other LPBF machined parts using standard clamping systems. Moreover, it is similar to the milling of conventionally produced parts, which were investigated by Bajić et al. [34]. The side milling showed a maximum Ra value of 1.42 , which was comparable to that of the conventionally clamped side-milling parts, as described by Chang and $\mathrm{Lu}$ [36]. The resulting roughness values were comparable with those of other LPBF manufactured and milled surfaces shown in the post-processing guidelines, introduced by Lammers et al. [37]. Finally, the roughness results were compared with those obtained for a rigid standard clamping system. Consequently, the bolt clamping system showed similar roughness results to those of a standard clamping system. Overall, the milling results highlighted the robustness of the bolt design for the milling process. Moreover, no chatter marks were observed.

The maximum shear-off torque required to remove the bolts was 7.1 Nm. Following the recommendations of Steinberg et al. [38] to limit the manual tractive force with fist closure to $170 \mathrm{~N}$ and assuming a hexagonal wrench with a lever of $80 \mathrm{~mm}$, a maximum manual torque of $13.6 \mathrm{Nm}$ was applied. Therefore, the measured shear-off torque was
Fig. 23 Shear-off results after all experiments were conducted for the different examined bolt concepts

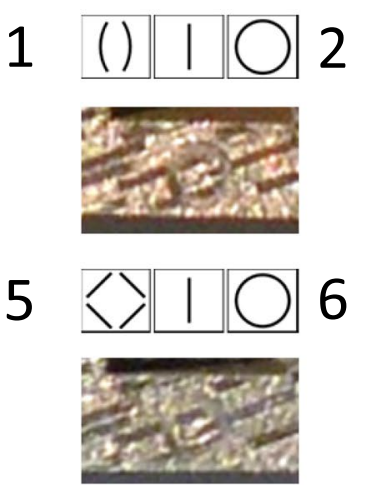

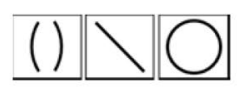
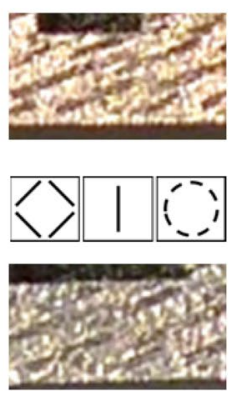
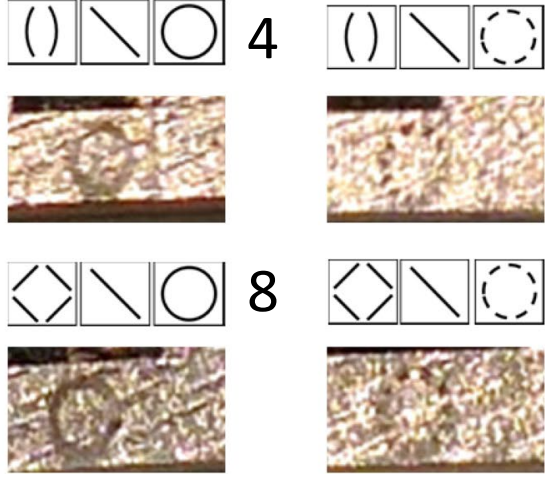
a)

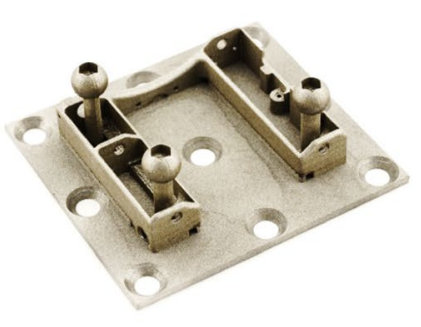

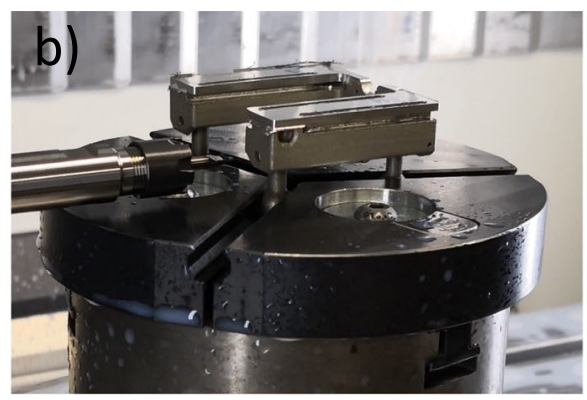

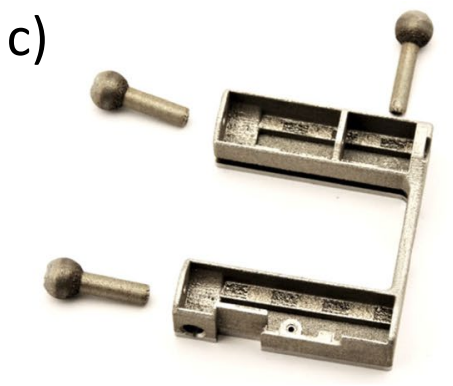

Fig. 24 a Inspection robotic housing after LPBF; b clamped condition during milling; $\mathbf{c}$ finished part obtained after milling and bolt removal

acceptable for the manual removal of the bolts. Moreover, the automated removal of bolts was possible. After the removal, the maximum residual material was $0.067 \mathrm{~mm}$, which is acceptable for most end-user applications. We observed differences of the measured shear-off torque and the simulated, most possibly caused by LPBF processrelated inaccuracies.

Both case studies applied a stepwise notch and a round interface. For the robot housing, the vertical shafts and stepwise notches were used, which had $0.3 \mathrm{~mm}$ smaller diameters than those of the previously used notches. For the aircraft bracket, inclined shafts were used with a notch of $45^{\circ}$ in the build direction. Moreover, the bolts for both case studies were added on the curved surfaces, which were not as plane as those of the test sample.

A close control of tolerances was essential for functional parts. The largest compliance in this study was measured on sample 2 with a displacement of $112 \mu \mathrm{m}$ at $1000 \mathrm{~N}$. A more realistic milling force of $250 \mathrm{~N}$ resulted in a displacement of $12.5 \mu \mathrm{m}$. The general engineering tolerances for a nominal dimension of 6-30 mm allow a maximum deviation of $\pm 200 \mu \mathrm{m}$ for the medium tolerance class [39]. The measured deformations of both case studies are well within this limit and confirm a sufficient accuracy of the milled surfaces. The exceptions are the slightly higher deviations on the milled surfaces where chatter marks occurred because of the vibration of the bracket.

The dynamic stability of both case studies showed dominant peaks of FRF, but the eigenmode and chatter marks, caused by the bolts, could be avoided. A difference in the amplitude of the dynamic compliance was observed between the cap and monolithic designs, as shown in Fig. 30. Contact interfaces are known as strong contributors to the overall damping of a structure. The additional interface introduced by the cap design can explain the much lower compliance at $818 \mathrm{~Hz}$.

The post-processing showed suitable milling results. Note that the chatter marks at positions two and three of the aircraft bracket (Fig. 31) were caused by the thin wall rather than the bolts and the clamping system. To guarantee a stable milling process without chattering, it is recommended to place the bolts close to the milling surfaces. Within the milling processes, the parts were not re-clamped. The deliberate choice of using the worst-case bolts highlighted the robustness and proved the practical applicability even in the worst-case scenario.

Several factors require to be considered to evaluate whether it is efficient to use the bolts. The additional build height, material volume, and build time are relevant cost drivers for bolt manufacturing. The additional effort required in the LPBF process of the bolts for a single part on one build platform is calculated and presented in Table 6. The aircraft bracket represents a large, weightoptimized part with a large height and relatively low material volume. This led to a low percentage of additional build time for the bolts. The positioning of one bolt near the top increased the height, which further increased the total build time. The cap design had a lower build height, material volume, and additional build time because of reusable caps. The robotic housing represents a compact, flat part, as well as a low material volume part. The bolts significantly exceeded the robotic housing. Both the additional volume and height led to a high percentage of additional build time. The test samples of the static and milling experiments had a relatively low height but a high material volume. This led to a relatively low percentage of additional build time and material volume. Compared to existing literature, this additional material consumption for integrated clamping interfaces is low [13]. A quicker and easier clamping of parts for post-processing compensates the additional effort of integrated bolts.

\subsection{Value of the design}

The use of bolts adds value by providing interfaces for clamping and handling, thus enabling the automation of AM process chains for customized parts.

This design can be easily adapted for other part geometries, which substantially simplifies the design process of AM parts, as the use of parallel surfaces for clamping is not 


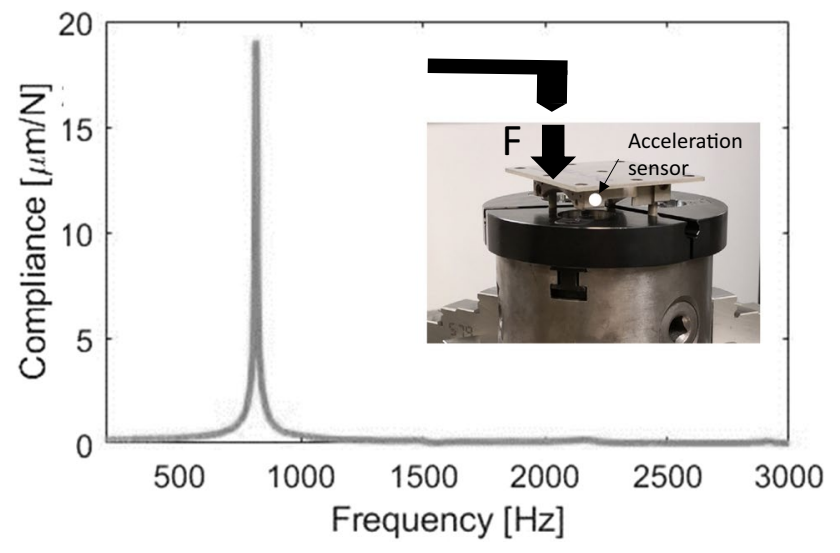

Fig. 25 Frequency response function of the robotic housing required. The bolts can be placed in different orientations and on various curved surfaces. Moreover, the part stiffness does not have to sustain the clamping loads.

The bolts can be integrated on surfaces that face away from the build platform. This orientation presents two advantages: (i) at an angle above $45^{\circ}$ to the build platform, no support is required and (ii) elements that need machining, such as support structures, usually face downward. These opposite positions enable ideal tool accessibility to most of post-machining surfaces.

The bolts are designed for an easy placement on any part. A standard shaft fits on a large range of positions on the AM part with a minimum design effort. The round head avoids bending or torsional stresses on the notch. Hence, the part is clamped even when the shafts have deviations. The straight shaft design enables a direct transfer of load from the AM part to the clamping system. However, in future, other designs should be used, e.g., monolithic design

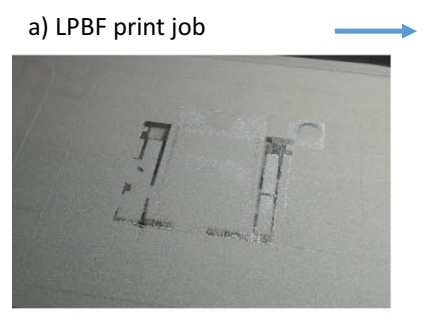

b) Printed part

c) Clamped part

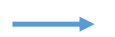

d) Shank cutter
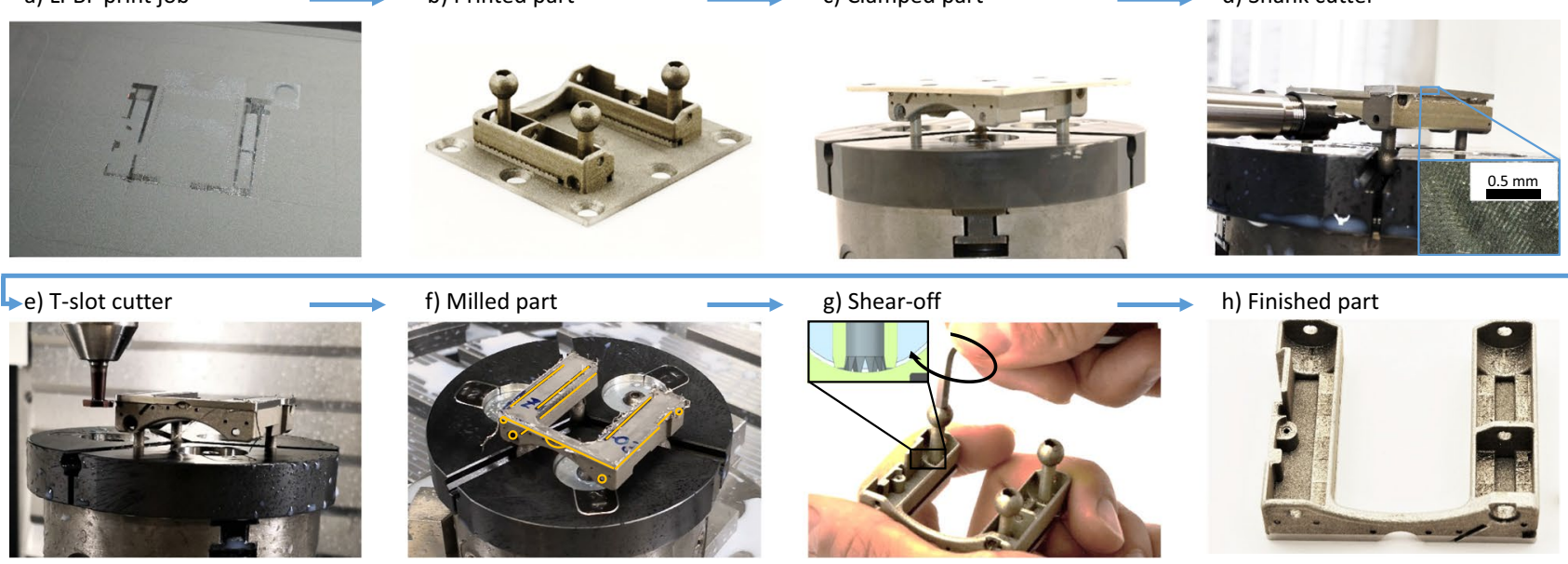

Fig. 26 Detailed manufacturing process of the vertical bolts on the robotic housing. a LPBF print job, b printed part, $\mathbf{c}$ clamped part, $\mathbf{d}$ shank cutter, e T-slot cutter, $\mathbf{f}$ milled part, $\mathbf{g}$ shear-off, $\mathbf{h}$ finished part

Fig. 27 Deviation between the CAD part and the LPBF part on the metallic sheet, $\mathbf{a}$ after LPBF manufacturing and after removal of the built plate, $\mathbf{b}$ after the milling process at the clamped position a)

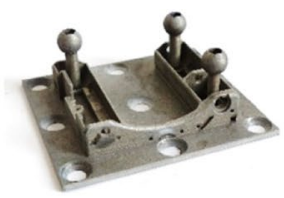

b)

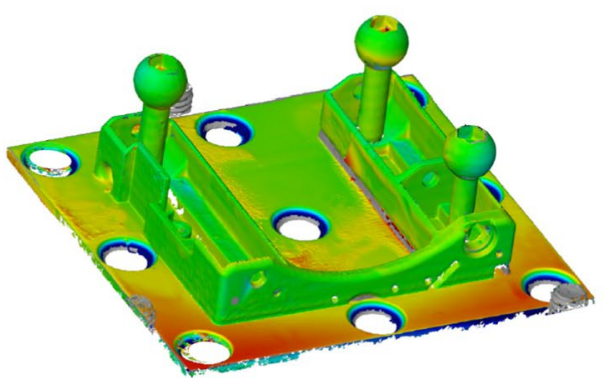

[mm]
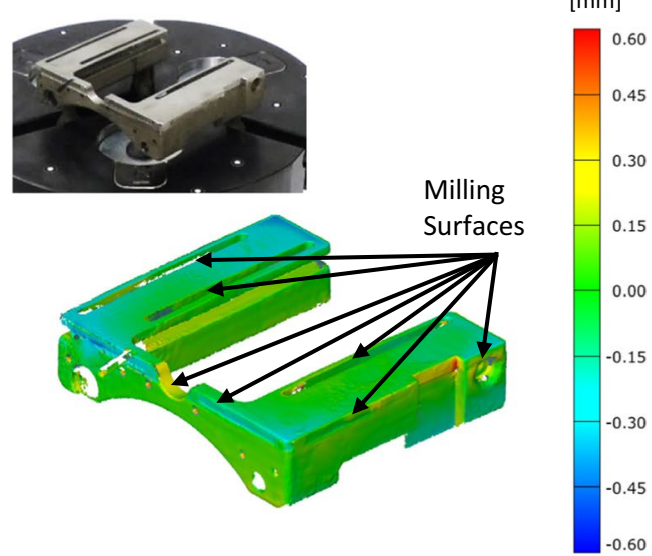

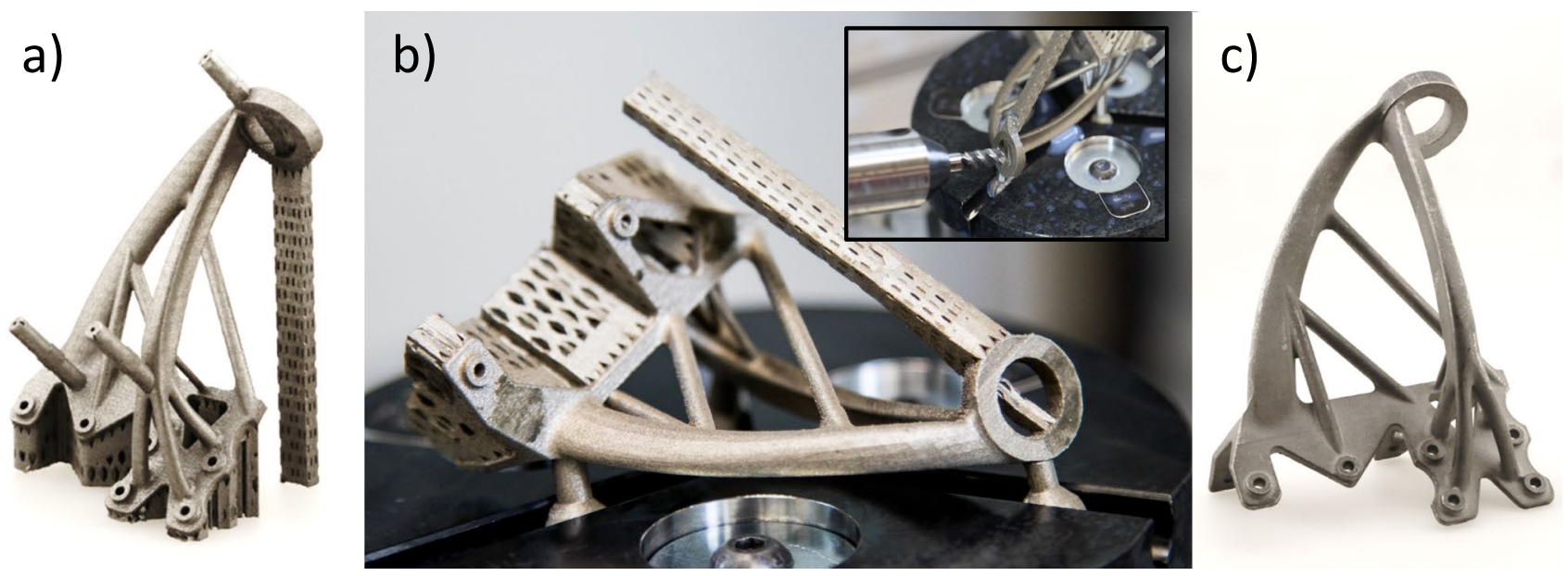

Fig. 28 Aircraft bracket; $\mathbf{a}$ after the LPBF manufacturing process; $\mathbf{b}$ under the clamped condition during the milling process; $\mathbf{c}$ after milling and bolt removal

Fig. 29 a Monolithic design with support; b cap design without support

Fig. 30 Frequency response function of the aircraft bracket for the cap and monolithic bolt designs a)

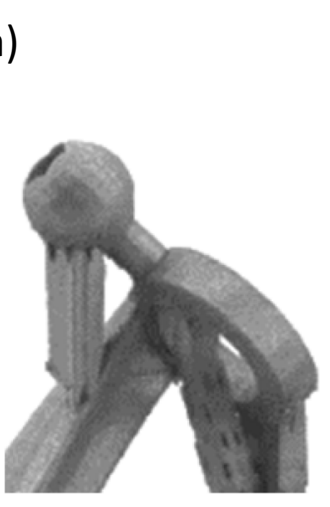

b)

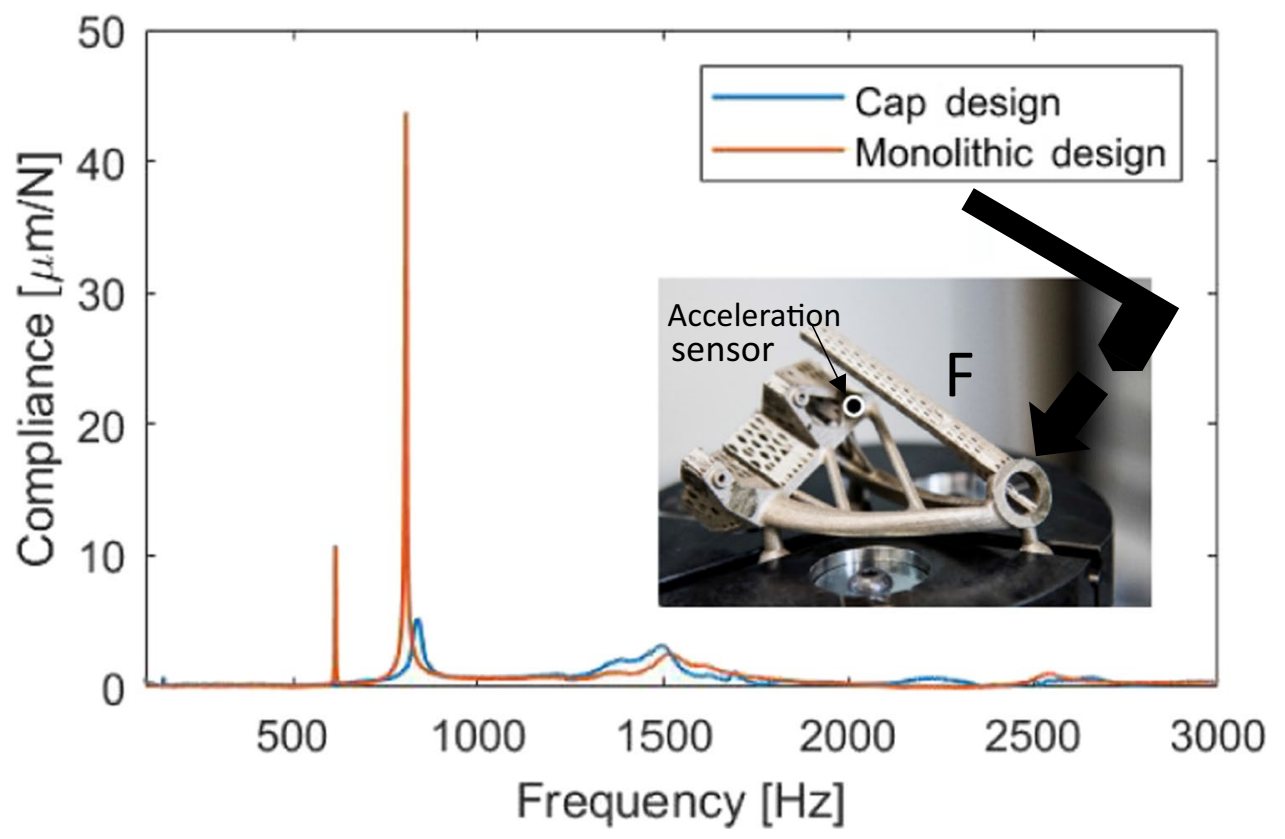




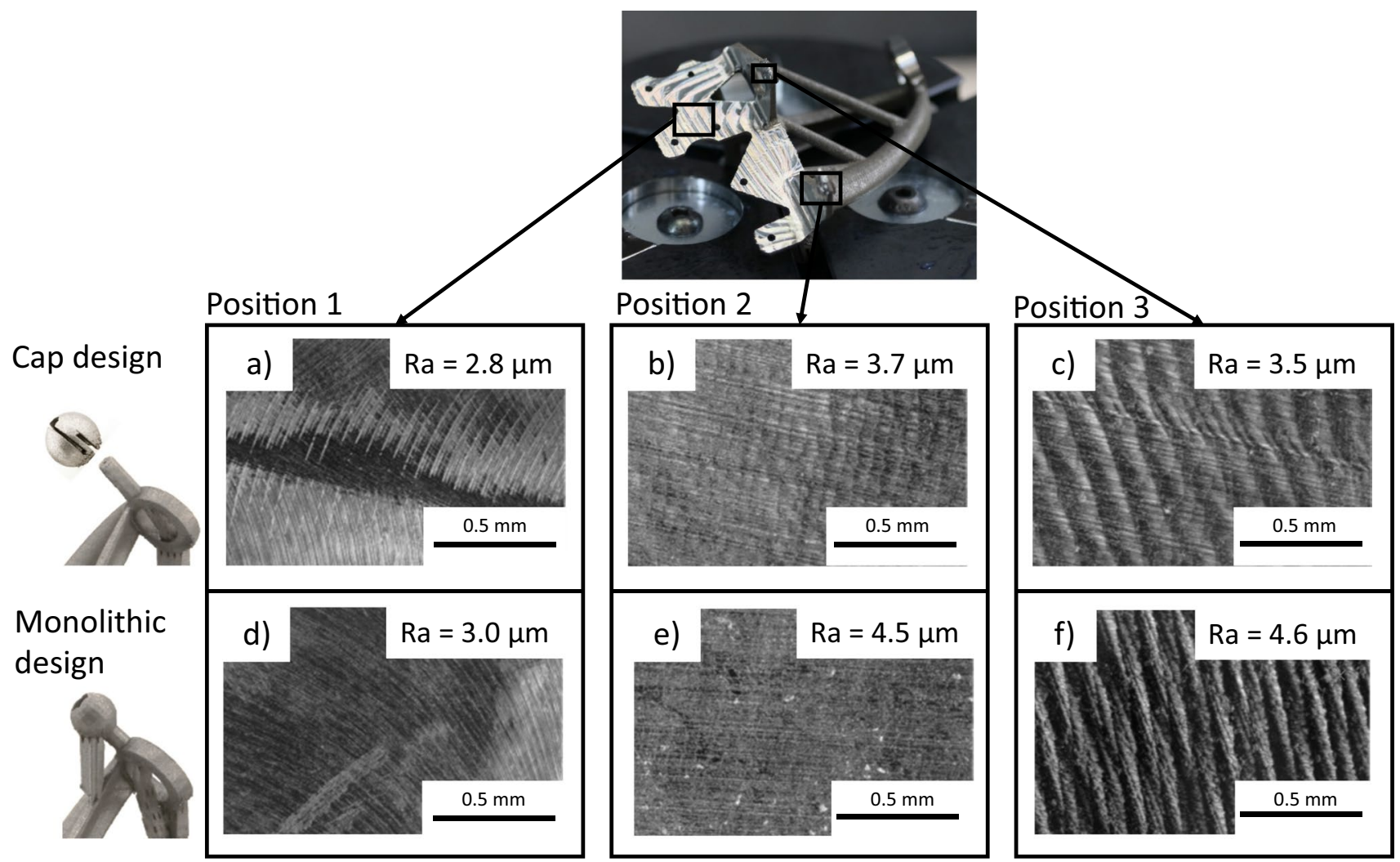

Fig. 31 Surface roughness after milling the aircraft bracket; $\mathbf{a}$ face milling process of the cap design; $\mathbf{b}$ side milling of the cap design; $\mathbf{c}$ side milling of the cap design; $\mathbf{d}$ face milling of the monolithic design; $\mathbf{e}$ side milling of the cap design; $\mathbf{f}$ side milling of the cap design

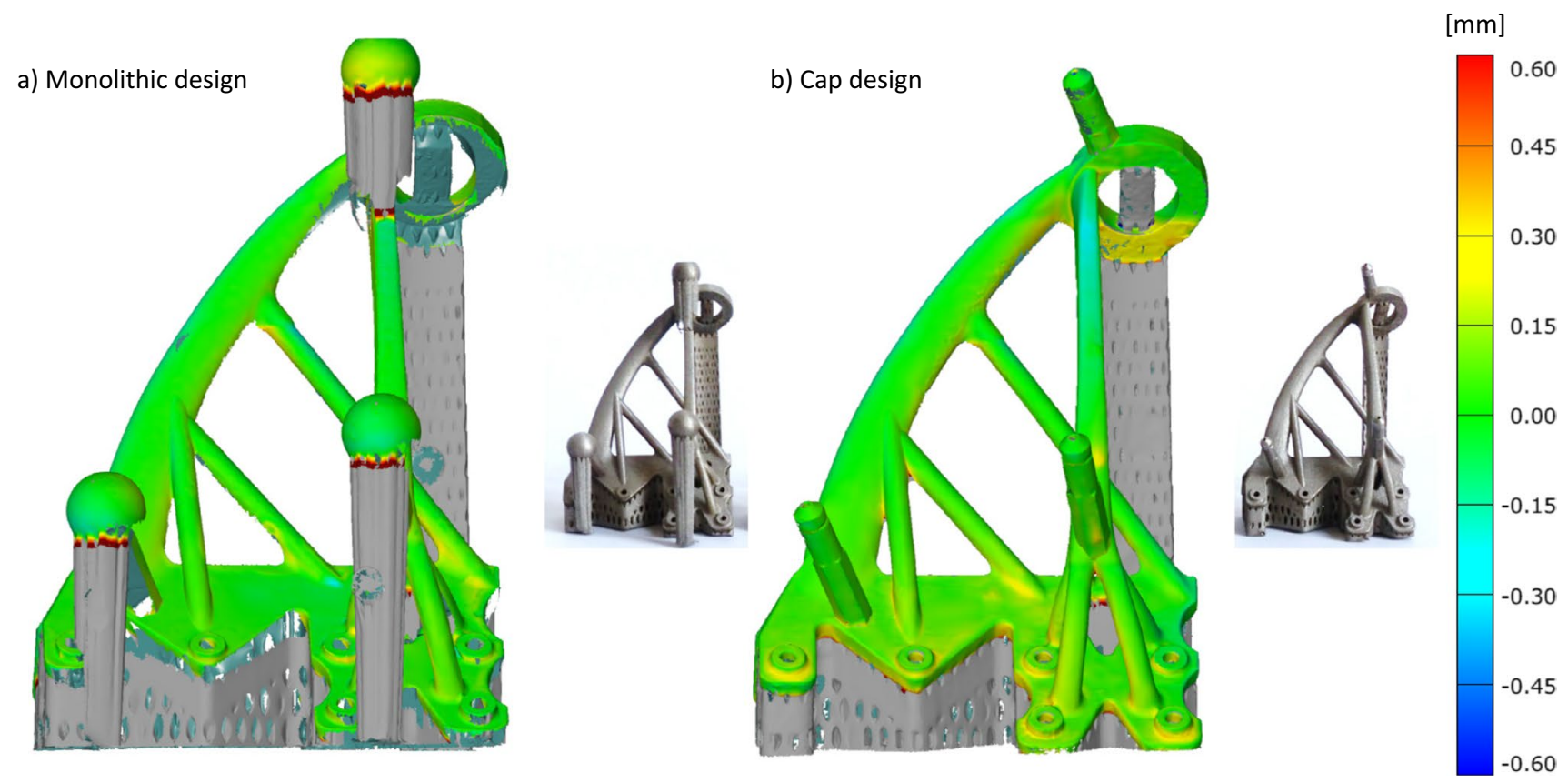

Fig. 32 Deviation between the 3D model and LPBF part after removal of the base blade: $\mathbf{a}$ for the monolithic design and $\mathbf{b}$ for the cap design 


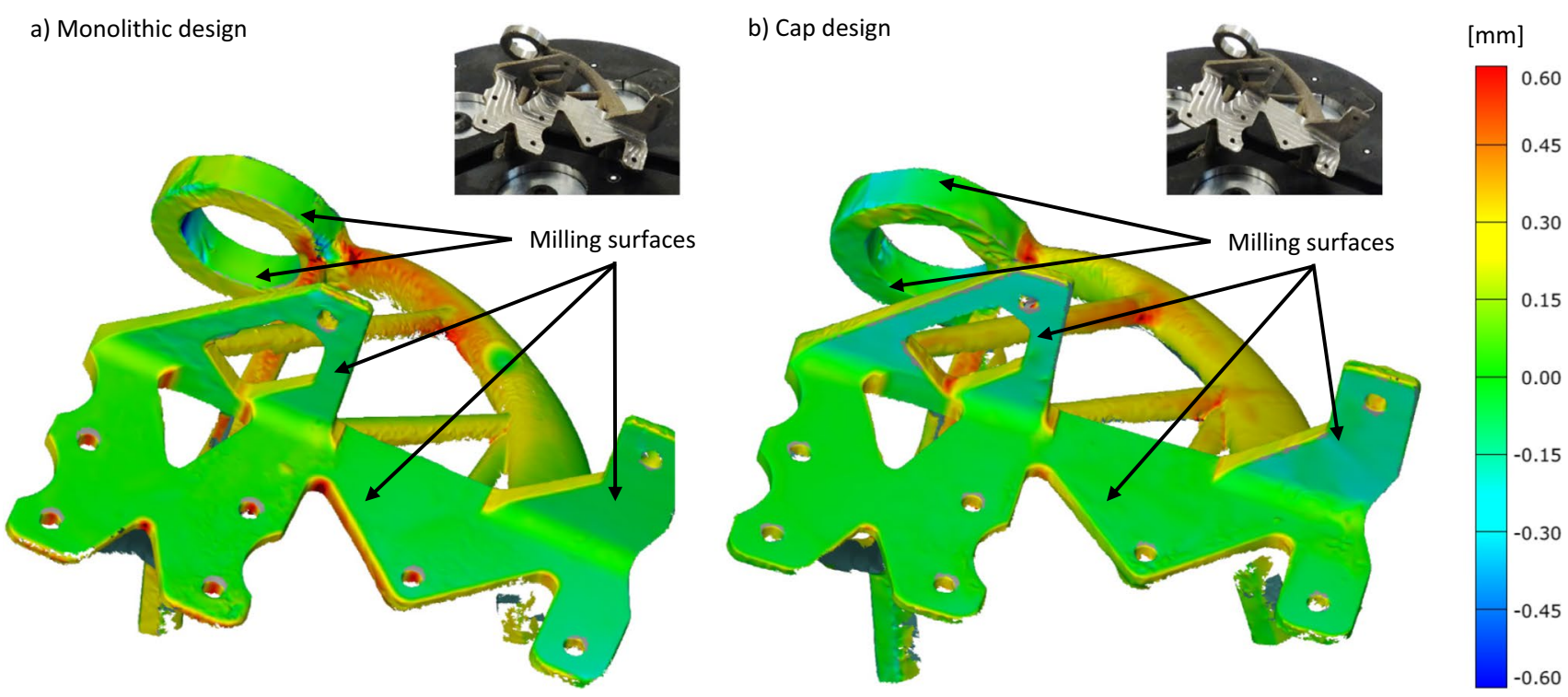

Fig. 33 Deviation between the CAD part and LPBF part and sheet metal, a after LPBF manufacturing and after build plate removal, $\mathbf{b}$ after the milling process at the clamped position

a) LPBF build job

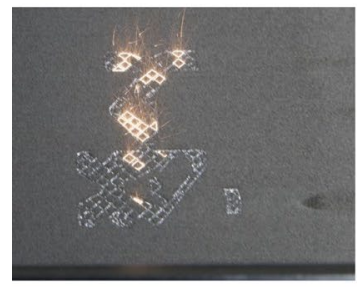

e) End - milling

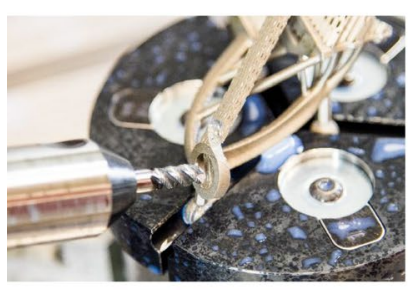

b) Printed part with monolithic bolts

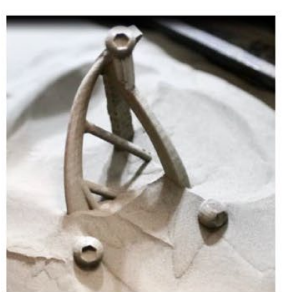

c) Monolithic bolt

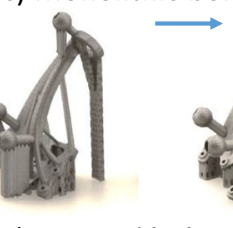

c) Cap and bolt
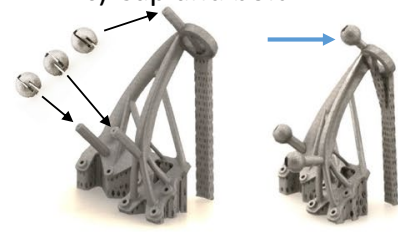

g) Monolithic bolt removal
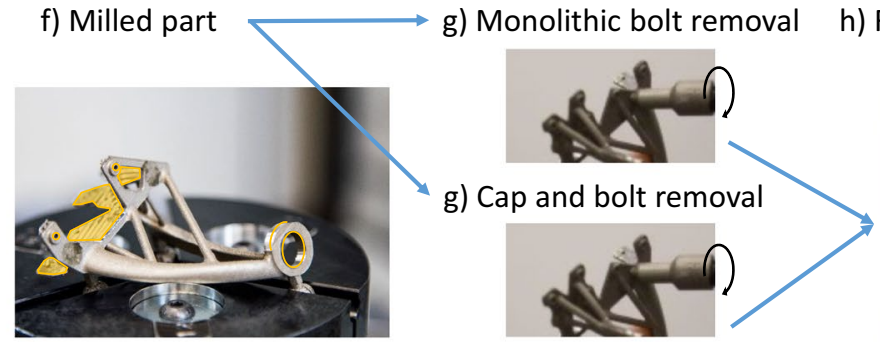

h) Finished part

d) Clamped part
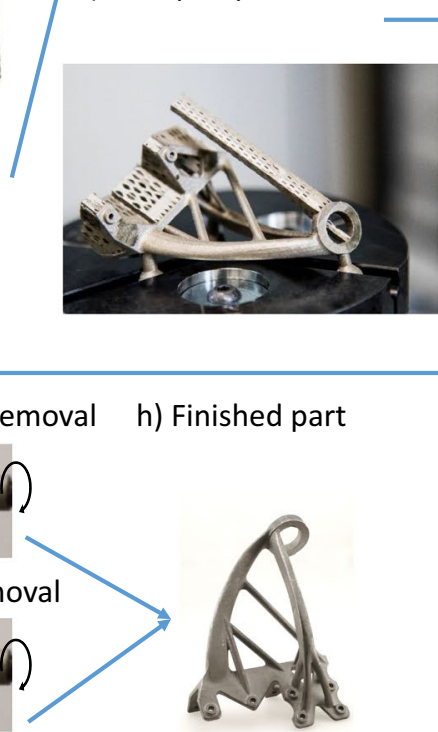

Fig. 34 Detailed manufacturing process of the inclined bolts on the aircraft bracket. a LPBF build job, b printed part with monolithic bolts, $\mathbf{c}$ monolithic bold, cap and bolt, $\mathbf{d}$ clamped part, e end-milling, $\mathbf{f}$ milled part, $\mathbf{g}$ monolithic both removal, cap and bolt removal, $\mathbf{h}$ finished part

variants with less support structure than the current design, especially when the bolt placement is automated.

Compared to other interfaces previously proposed by Chen et al. [15] and Boonsuk and Frank [13], the tool accessibility of LPBF parts was increased to five sides by combining the three jaw-clamping system proposed by Relea et al. [27] and Schlüssel et al. [28] with integrated, supportfree bolts. Furthermore, handling techniques, such as bolt removal, were significantly improved.

The use of bolts enables clamping for a large number of post-machining applications and the part's position in the clamping system is already defined using the $3 \mathrm{D}$ model. The 
position detection of the complex AM part is not necessary when a small deviation occurs on the LPBF part. For both case studies, no position detection was applied.

The 3D scans of the aircraft bracket and robotic housing measured a global maximum deviation of $0.6 \mathrm{~mm}$ between the as-build LPBF part and the 3D model, caused by local process inaccuracies. The maximum deviation of the bolt interfaces after the build plate removal was $0.1 \mathrm{~mm}$ for the aircraft bracket and $0.15 \mathrm{~mm}$ for the robotic housing. For both case studies, a maximum deviation of $0.3 \mathrm{~mm}$ was measured at the clamped position because of the deviation in the bolts. Therefore, an additional offset was added on the surfaces to be machined. The required IT-class 12 according to EN ISO 286-1 was achieved for both case studies. A general recommendation is not possible to state because the deviation depends on the part's geometry, the AM process, and the post-treatments. The thermally induced deviation of an AM part can be further reduced using heat treatment [40]. The integrated interfaces can be used for gripping and handling by industrial robots, thus enabling the mass customization and series production of individual lightweight parts.

The bolt concept is especially interesting for a large range of industry sectors, especially for medical and dental sectors, which require mass customization. Moreover, it is useful for the automotive and aerospace industry sectors where topology-optimized lightweight parts are required in large batch sizes.

However, there are limitations to the application of integrated bolts. Very small parts or large parts are difficult to clamp. Moreover, fragile or thin-walled parts, such as lattice structures, are difficult to clamp using any mechanical clamping system.

\subsection{Process automation and outlook}

This study applied LPBF, which is a commonly used metal AM process. The primary advantages of this process are the NNS manufacturing of complex and individualized shapes. However, LPBF requires support on overhanging surfaces and in vertical channels above a certain diameter, according to the material-specific guidelines presented by Kranz et al. [41]. As shown in this study, the supports can be milled entirely. Milling the support structures causes intense wear on the milling tool. Further research is needed to optimize the shape of the support structure and reduce tool wear[42]. In future, the applicability of the proposed bolts should be investigated in other metal AM processes. One possible example of this is electron beam melting, which is a process with an acceptable NNS [43]. Furthermore, other plastic AM processes, such as FDM or SLS, require extensive postprocessing but lower machining forces compared to metal AM. Thus, the bolt concept can be used in such processes.
This study successfully applied finish milling, which is the most used post-process for LPBF parts. For this process, a maximum load introduction of $250 \mathrm{~N}$ was assumed according to Fortunato et al. [29] and Ozcelik, Kuram and Simsek[30]. Other post-machining processes for AM parts, such as grinding and thread cutting, introduced higher loads and must be investigated to validate the applicability of bolts.

This study built on a three-jaw chuck proposed by Schlüssel et al. [28] and introduced integrated interfaces to clamp AM parts. Its primary advantage over other mechanical clamping systems such as from Lang Technik [20] or Bakker et al. [22] is that no workpiece deformation occurs because of the induced clamping forces. The concept of integrated bolts does not require any cleaning before and after machining as that required for adhesive workpiece holding [23, 24], as well as provides an interface for handling. This approach allows clamping and handling at a minimum, or even without, manual operations. Moreover, it creates an additional form closure and has five-sided tool accessibility. Overall, because of the positive location criterion, the three bolts can be freely placed on the part.

The bolts are intended to be used as an interface for robotic handling, which accelerates the part with up to $13 \mathrm{~g}$ [10]. This induces a force of $37 \mathrm{~N}$ for the test sample $(m=295 \mathrm{~g}), 11 \mathrm{~N}$ for the robot housing $(m=88 \mathrm{~g})$, and $8 \mathrm{~N}$ for the aircraft bracket $(m=65 \mathrm{~g})$. Therefore, this study focused on clamping, which is the most critical step for process automation because of the generation of high forces. However, to validate the entire process chain, the robotic aspects of gripping and handling and the automated powder removal should be investigated based on an algorithm derived from the $\mathrm{CAD}$ and a simulation, developed by Kiener [44], and investigated by Hunter et al. [45].

The part with the maximum build height in this study was the aircraft bracket with a height of $80 \mathrm{~mm}$. To further increase the applications, larger build sizes require to be investigated. Larger parts increase the clamping distances, levers, and forces. Integrating bolts into larger parts requires investigations on how to ensure a safe and stable machining. One possible solution are additional bolts that are connected to a clamping system with telescopic rods.

The monolithic ball interface of the inclined shaft on the aircraft bracket requires support, which hinders the complete automation of the post-process chain. Moreover, the case study presents a separately manufactured reusable cap to avoid this support. Furthermore, the reusable cap reduces the bolt height and volume. The caps are currently manufactured by $\mathrm{AM}$ and can be mass-produced in future.

The functional sheet metal concepts for LPBF, which are visible on the inspection housing, as well as by Schaub et al. [46], can be an additional facilitator for process automation. The metallic sheet can reduce the material waste and avoid support structures. This concept needs to be further 
developed to enable the machining of smaller parts, more fragile parts with thin walls, such as lattice structures, and to reduce the AM build job time.

Further steps in the development of integrated bolts are guidelines for bolt positioning and orientation. An explicit guideline is the basis for algorithms to automate the bolt placement, similar to the state-of-the-art automated support structure generation. Boonsuk and Frank [13] already proposed an algorithm for tool path generation for other clamping interfaces of AM parts. This should be adopted and improved for the bolts presented in this study.

\section{Conclusion}

This study introduces a new design and concept of integrated bolts as an interface for handling and clamping of AM parts. A force of $250 \mathrm{~N}$ resulted in a maximum displacement of $12.5 \mu \mathrm{m}$. The milling results demonstrated a maximum $\mathrm{Ra}$ value of $1.42 \mu \mathrm{m}$. After removing the bolts, a maximum residual height of $0.067 \mathrm{~mm}$ remained. The following conclusions were drawn.

- The proposed bolt design is robust against milling forces and can be applied to many AM part geometries as standardized clamping and robotic handling interfaces.

- The proposed clamping system does not induce any force on the AM parts, which is beneficial for load-optimized AM parts.

- This is the first study in which the bolt design enables five-sided tool accessibility for LPBF parts during machining and therefore significantly reduces the need for re-clamping.

- The bolts offer additional design freedom for AM parts and simplify the design process compared to the conventional parallel clamping interfaces.

- The bolts can be easily removed using a wrench and leave only little residual material.

The practical performance of the bolt is highlighted using two industrial case studies in which the entire milling processes were successfully performed at one clamped position. The integrated bolts act as a key enabler of automated AM processes. Thus, using the proposed method, the AM technology can be used in industrial series production. Researchers and practitioners are invited to apply the integrated bolts in their applications and extend their impact beyond the scope of this study.

Acknowledgements A special thanks go to Lukas Weiss, Eduard Relea and Martin Postel from the inspire AG as well as Dario Fenner from $\mathrm{pdlz}$ for their technical support.
Author contribution Julian Ferchow: Conceptualization; methodology; validation; formal analysis; compliance simulation; experimental, investigation; writing - original draft; visualization; acquisition of 3D scan measurement data; acquisition build time data; funding acquisition; project management.

Dominik Kälin: Inspection robot bolt design, compliance simulation, compliance experiment.

Gokula Englberger: Aircraft bracket bolt design, frequency response function measurement.

Marcel Schlüssel: Conceptualization, methodology, formal analysis, investigation, funding acquisition.

Christoph Klahn: Project administration, writing — review and editing.

Mirko Meboldt: Funding acquisition, writing — review and editing.

Funding Open access funding provided by Swiss Federal Institute of Technology Zurich. The authors thank the Innosuisse for financing this project under the grant 35194.1 IP-ENG.

Availability of data and materials Not applicable.

\section{Declarations}

Ethics approval Not applicable.

Competing interests The authors declare no competing interests.

Open Access This article is licensed under a Creative Commons Attribution 4.0 International License, which permits use, sharing, adaptation, distribution and reproduction in any medium or format, as long as you give appropriate credit to the original author(s) and the source, provide a link to the Creative Commons licence, and indicate if changes were made. The images or other third party material in this article are included in the article's Creative Commons licence, unless indicated otherwise in a credit line to the material. If material is not included in the article's Creative Commons licence and your intended use is not permitted by statutory regulation or exceeds the permitted use, you will need to obtain permission directly from the copyright holder. To view a copy of this licence, visit http://creativecommons.org/licenses/by/4.0/.

\section{References}

1. Attaran M (2017) The rise of 3-D printing: the advantages of additive manufacturing over traditional manufacturing. Bus Horiz 60:677-688. https://doi.org/10.1016/j.bushor.2017.05.011

2. Deradjat D, Minshall T (2017) Implementation of rapid manufacturing for mass customisation. J Manuf Technol Manag 28:95121. https://doi.org/10.1108/JMTM-01-2016-0007

3. Flynn JM, Shokrani A, Newman ST, Dhokia V (2016) Hybrid additive and subtractive machine tools - research and industrial developments. Int J Mach Tools Manuf 101:79-101. https://doi. org/10.1016/j.ijmachtools.2015.11.007

4. Manogharan G, Wysk RA, Harrysson OLA (2016) Additive manufacturing-integrated hybrid manufacturing and subtractive processes: economic model and analysis. Int J Comput Integr Manuf 29:473-488. https://doi.org/10.1080/0951192X.2015.1067920

5. Le VT, Paris H, Mandil G (2017) Process planning for combined additive and subtractive manufacturing technologies in a remanufacturing context. J Manuf Syst 44:243-254. https://doi.org/10. 1016/j.jmsy.2017.06.003

6. Wohlers Report, Wohlers Associates, Fort Collins, 2020. 
7. Salmi A, Calignano F, Galati M, Atzeni E (2018) An integrated design methodology for components produced by laser powder bed fusion (L-PBF) process. Virtual Phys Prototyp 13:191-202. https://doi.org/10.1080/17452759.2018.1442229

8. M. Galati, F. Calignano, M. Viccica, L. Iuliano, Additive manufacturing redesigning of metallic parts for high precision machines, Crystals. 10 (2020). https://doi.org/10.3390/cryst10030161.

9. C. Klahn, D. Omidvarkarjan, M. Meboldt, Industrializing additive manufacturing - proceedings of additive manufacturing in products and applications - AMPA2017, 1 (2018) 3-13. https:// doi.org/10.1007/978-3-319-66866-6.

10. Nabat V, De La M, Rodriguez O, Company O, Krut S, Pierrot F, Par4: very high speed parallel robot for pick-and-place, (2005) IEEE/RSJ Int. Conf Intell Robot Syst IROS 2005:553-558. https:// doi.org/10.1109/IROS.2005.1545143

11. O.M. Kushnarenko, Entscheidungsmethodik zur Anwendung generativer Verfahren für die Herstellung metallischer Endprodukte, Shak. Verlag Aachen. (2009). https://www.shaker.de/de/content/ catalogue/index.asp?lang=de \&ID=8\&ISBN=978-3-8322-8121-2.

12. M. Blair, T.L. Stevens, Steel castings handbook, ASM International, 1995.

13. Boonsuk W, Frank MC (2009) Automated fixture design for a rapid machining process. Rapid Prototyp J 15:111-125. https://doi.org/ 10.1108/13552540910943414

14. H. Spinivasan, Automated model processing and localization of additively manufactured parts for finish machining, North Carolina State University, 2016.

15. Chen N, Barnawal P, Frank MC (2018) Automated post machining process planning for a new hybrid manufacturing method of additive manufacturing and rapid machining. Rapid Prototyp J 24:1077-1090. https://doi.org/10.1016/j.promfg.2019.06.140

16. Chen N, Frank M (2019) Process planning for hybrid additive and subtractive manufacturing to integrate machining and directed energy deposition. Procedia Manuf 34:205-213. https://doi.org/10. 1016/j.promfg.2019.06.140

17. Leutenecker-Twelsiek B (2019). Additive Fertigung in der industriellen Serienproduktion: Bauteilidentifikation und Gestaltung. https:// doi.org/10.3929/ethz-a-010782581

18. Schmelzle J, Kline EV, Dickman CJ, Reutzel EW, Jones G, Simpson TW (2015) (Re)Designing for part consolidation: understanding the challenges of metal additive manufacturing. J Mech Des Trans ASME 137:1-12. https://doi.org/10.1115/1.4031156

19. Bi ZM, Zhang WJ (2001) Flexible fixture design and automation: review, issues and future directions. Int J Prod Res 39:2867-2894. https://doi.org/10.1080/00207540110054579

20. G. Lang, Makro-Grip 5-Achs-Spanner, (2020) https://www.langtechnik.de/de/produkt/katalog-201. https://www.lang-technik.de/de/ produkt/katalog-2019/makro-grip-125-125.html.

21. Tohidi H, AlGeddawy T (2019) Change management in modular assembly systems to correspond to product geometry change. Int J Prod Res 57:6048-6060. https://doi.org/10.1080/00207543.2018. 1559374

22. Bakker OJ, Papastathis TN, Popov AA, Ratchev SM (2013) Active fixturing: literature review and future research directions. Int J Prod Res 51:3171-3190. https://doi.org/10.1080/00207543.2012.695893

23. De Meter EC (2004) Light activated adhesive gripper (LAAG) workholding technology and process. J Manuf Process 6:201-214. https://doi.org/10.1016/j.jaci.2012.05.050
24. E.C. De Meter, J. Santhosh Kumar, Assessment of photo-activated adhesive workholding (PAW) technology for holding "hard-to-hold" workpieces for machining, J. Manuf. Syst. 29 (2010) 19-28. https:// doi.org/10.1016/j.jmsy.2010.06.006.

25. J. Campbell, Complete casting handbook: metal casting processes, metallurgy, techniques and design: second edition, ButterworthHeinemann, 2015. https://doi.org/10.1016/C2014-0-01548-1.

26. Rico JC, Valiño G, Mateos S, Cuesta E, Suárez CM (2000). Automatic selection of clamping surfaces in the turning process for rotational parts. https://doi.org/10.1243/0954405001518071

27. Relea E, Weiss L, Schlüssel M, Wegener K (2019) Novel clamping system for machine tools. International Conference on Competitive Manufacturing Proceedings - COMA 19:220-226

28. M. Schlüssel, E. Relea, L. Weiss, Method, device, and aid element for mounting a workpiece, 2019. https://doi.org/10.3929/ethz-b000391119.

29. Fortunato A, Lulaj A, Melkote S, Liverani E, Ascari A, Umbrello D (2018) Milling of maraging steel components produced by selective laser melting. Int J Adv Manuf Technol 94:1895-1902. https://doi. org/10.1007/s00170-017-0922-9

30. Ozcelik B, Kuram E, Simsek BT (2011) Comparison of dry and wet end milling of AISI 316 stainless steel. Mater Manuf Process 26:1041-1049. https://doi.org/10.1080/10426914.2010.515645

31. Özşahin O, Özgüven HN, Budak E (2010) Analysis and compensation of mass loading effect of accelerometers on tool point FRF measurements for chatter stability predictions. Int J Mach Tools Manuf 50:585-589. https://doi.org/10.1016/j.ijmachtools.2010.02. 002

32. Zhang C, Wang S, Li J, Zhu Y, Peng T, Yang H (2020) Additive manufacturing of products with functional fluid channels: a review. Addit Manuf 36:101490. https://doi.org/10.1016/j.addma.2020. 101490

33. R.J. Williams, J. Al-Lami, P.A. Hooper, M.-S. Pham, C.M. Davies, Creep deformation and failure properties of $316 \mathrm{~L}$ stainless steel manufactured by laser powder bed fusion under multiaxial loading conditions, Addit. Manuf. (2020) 101706. https://doi.org/10.1016/j. addma.2020.101706.

34. D. Bajić, B. Lela, Ž. Dražen, Modeling of machined surface roughness and optimization of cutting parameters in face milling, Metalurgija. 47 (2008) 331-334. https://hrcak.srce.hr/26042.

35. Chang CK, Lu HS (2006) Study on the prediction model of surface roughness for side milling operations. Int J Adv Manuf Technol 29:867-878. https://doi.org/10.1007/s00170-005-2604-2

36. Ching-Kao C, Lu HS (2007) The optimal cutting-parameter selection of heavy cutting process in side milling for SUS304 stainless steel. Int J Adv Manuf Technol 34:440-447. https://doi.org/10.1007/ s00170-006-0630-3

37. S. Lammers, J. Tominski, D. Zimmer, Guidelines for a post processing oriented design of additive manufactured parts for use in topology optimization, 27 (2015) 4-5. https://congress.cimne.com/ sim-am2019/admin/files/fileabstract/a184.pdf.

38. U. Steinberg, F. Liebers, A. Klußmann, Manuelle Arbeit ohne Schaden, (2011) 1-24. https://www.baua.de/DE/Angebote/Publi kationen/Praxis/A55.pdf?_blob=publicationFile \&v=4.

39. D.I. 2768-1, 2768-1 DIN ISO 2768-1: Allgemeintoleranzen; Toleranzen für Längen-und Winkelmaße ohne einzelne Toleranzeintragung, (1991). 
40. C. Li, Z.Y. Liu, X.Y. Fang, Y.B. Guo, Residual stress in metal additive manufacturing, in: Procedia CIRP, Elsevier B.V., 2018: pp. 348-353. https://doi.org/10.1016/j.procir.2018.05.039.

41. Kranz J, Herzog D, Emmelmann C (2015) Design guidelines for laser additive manufacturing of lightweight structures in TiAl6V4. J Laser Appl 27:S14001. https://doi.org/10.2351/1.4885235

42. Tripathi V, Armstrong A, Gong X, Manogharan G, Simpson T, De Meter E (2018) Milling of Inconel 718 block supports fabricated using laser powder bed fusion. J Manuf Process 34:740-749. https:// doi.org/10.1016/j.jmapro.2018.03.046

43. Dolimont A, Michotte $S$, Lorphèvre ER, Ducobu F, De Formanoir C, Godet S, Filippi E (2015) Characterisation of electron beam melting process on Ti6Al4V in order to guide finishing operation. Int J Rapid Manuf 5:320. https://doi.org/10.1504/ijrapidm.2015.074811

44. C. Kiener, Removing filling material from a cavity in a component and apparatus for preforming same, 2019. https://patents.justia.com/ inventor/christoph-kiener.
45. Hunter LW, Brackett D, Brierley N, Yang J, Attallah MM (2020) Assessment of trapped powder removal and inspection strategies for powder bed fusion techniques. Int J Adv Manuf Technol 106:45214532. https://doi.org/10.1007/s00170-020-04930-w

46. A. Schaub, B. Ahuja, L. Butzhammer, J. Osterziel, M. Schmidt, M. Merklein, Additive manufacturing of functional elements on sheet metal, in: Phys. Procedia, Elsevier B.V., 2016: pp. 797-807. https:// doi.org/10.1016/j.phpro.2016.08.082.

Publisher's Note Springer Nature remains neutral with regard to jurisdictional claims in published maps and institutional affiliations. 